\title{
1 Suppression of PIK3CA-driven epileptiform activity by acute pathway
}

\section{control}

3

Achira Roy ${ }^{1, *}$, Victor Z. Han ${ }^{1,2}$, Angela M. Bard ${ }^{1}$, Devin T. Wehle ${ }^{1,3}$, Stephen E. P.

${ }^{1}$ Center for Integrative Brain Research, Seattle Children's Research Institute, Seattle, Washington, USA; ${ }^{3}$ Graduate Program in Neuroscience and Departments of ${ }^{2}$ Biology, University of Washington, Seattle, Washington, USA.

Seattle Children's Research Institute,

Center for Integrative Brain Research

Seattle, WA, USA. ZIP: 98101 
27 Competing Interests Statement: All authors read and approved the final manuscript.

28 None of the authors have competing interests.

Short title: Acute suppression of PIK3CA-driven epilepsy

31 Keywords: PI3K; epilepsy; mouse model; preclinical drug screens; BKM120; RAD001;

34 Number of Figures: 5

35 Number of Tables: 1

36 Number of Figure supplements: 7 


\section{ABSTRACT}

38 Patients harboring mutations in the PI3K-AKT-MTOR signaling pathway often develop a spectrum of neurodevelopmental disorders including epilepsy. A significant proportion of

40 them remain unresponsive to conventional anti-seizure medications. Understanding

41 mutation-specific pathophysiology is thus critical for molecularly targeted therapies. We

42 previously determined that mouse models expressing patient-related activating mutation

43 in PIK3CA are epileptic and acutely treatable with PI3K inhibition, irrespective of

44 dysmorphology (Roy et al. 2015). Using the same mutant model, we have now identified

45 physiological mechanisms underlying the dysregulated neuronal excitability and its

46 acute attenuation. We show that Pik3ca-driven hyperexcitability in hippocampal

47 pyramidal neurons is mediated by changes in multiple non-synaptic, cell-intrinsic

48 properties. These are distinct from mechanisms driving epilepsy in TSC/RHEB

49 models. Further, we report that acute inhibition of PI3K or AKT, but not MTOR,

50 suppresses the intrinsic epileptiform nature of the mutant neurons. These data

51 represent an important step towards precision therapeutics against intractable

52 epilepsy, using pathway drugs originally developed as anti-cancer agents. 


\section{INTRODUCTION}

Mutations in the PI3K-AKT-MTOR signaling pathway, long studied for roles in cancer (Madsen 2020; Yang et al. 2019), also cause clinically important developmental brain overgrowth syndromes. Affected individuals display phenotypes ranging from dysplastic megalencephaly, hemimegalencephaly and focal cortical dysplasia, as well as comorbidities including hydrocephalus, autism and intellectual disability (Bast et al. 2006; Blumcke et al. 2011; Mirzaa 2018; Stafstrom and Carmant 2015; Dobyns and Mirzaa 2019; Crino 2016). These mutations also cause focal epilepsy, representing 25$50 \%$ of all cases of intractable (treatment-resistant) epilepsy in children (Bast et al. 2006; Blumcke et al. 2011; Kim and Lee 2019; Mirzaa 2018; Stafstrom and Carmant activation may not be the sole arm of this complex signaling pathway accounting for all 
Here we assess acute mechanisms driving epileptiform activity in Nestin-

77 cre;Pik3ca ${ }^{E 545 K}$ mouse model harboring a patient-related activating mutation in Pik3ca,

78 encoding the p110a catalytic subunit of PI3K (Roy et al. 2015). We report that Pik3ca

79 overactivation causes intrinsic neuronal changes leading to hyperexcitability. We further

80 establish that this epileptiform activity is acutely dependent on AKT, but not MTOR,

81 regulation. Our study defines key aspects of acute neuronal dysregulation in an

82 important genetic epilepsy model, which we leverage to repurpose the available PI3K

83 pathway inhibitors against intractable epilepsy. 


\section{RESULTS}

\section{In vivo recordings demonstrate network hyperexcitability in mutant CA1}

Pik3ca mutant mouse models recapitulate patient phenotypes including brain overgrowth, cortical dysplasia, hydrocephalus and epilepsy, with phenotypic severity dependent on the mutant allele and its time of activation (Roy et al. 2019; Roy et al. 2015). Moreover, this developmental epilepsy is dissociable from dysmorphology and acutely suppressible by 1-hour in vivo administration of the pan-PI3K inhibitor BKM120 (Maira et al. 2012; Roy et al. 2015). To identify the underlying dynamic mechanisms, we performed in vivo and in vitro electrophysiological studies primarily focused on hippocampal pyramidal neurons, since the connection between epilepsy and hippocampal pathophysiology is well documented in patients and model systems, including ours (Roy, Millen, and Kapur 2020; Chatzikonstantinou 2014; Mazumder, Patial, and Singh 2019; Berdichevsky et al. 2013; Roy et al. 2015).

We investigated in vivo changes in the hippocampal CA1 network activity of P70 Nestin-cre;Pik3caE545K mutant mice relative to control littermates using local field potential (LFP) recordings, while simultaneously monitoring cortical surface activity by electrocorticography (ECoG). These recordings showed spontaneous interictal spike activity either restricted to the cortex or the hippocampus exclusively, or concurrent to the two regions in the mutant mice (Figure 1A-C; Figure 1 - figure supplement $1 A-D$ ). A broad spectrum of spike patterns was observed, consisting of single or groups of interictal spikes, the simplest identifiable unit of epileptiform activity (McCormick and Contreras 2001), as well as trains of sharp spikes, low-frequency slow waves or highfrequency low-amplitude "brushing events". These epileptiform events were observed 
exclusively in the mutant mice. Within the mutant group, the event frequency was significantly higher in the hippocampus than in the neocortex (Figure 1D). Power spectrum analyses revealed that the mutant hippocampi exhibit significantly higher power in the gamma frequency bands (Figure $1 \mathrm{E}-\mathrm{H})$, which is often indicative of seizure onset (Hughes 2008; Lee, Spencer, and Spencer 2000). These observations indicate that Pik3ca overactivation caused significant neural hyperexcitability in our mice, predominantly in the hippocampus.

\section{Mutant CA1 has elevated, acutely regulatable network excitability in vitro}

To assess the physiological aspects of Pik3ca-driven epilepsy at the tissue level, we performed hippocampal extracellular field recordings in acute forebrain slices. First, we conducted these recordings in P16-20 CA1 pyramidal layer, across a potassium concentration gradient in the recording buffer ([K+]: $3 \mathrm{mM}$ to $12 \mathrm{mM}$; Figure $2 \mathrm{~A}-\mathrm{C})$. This standard model shifts wild-type neuronal network from a silent state to tonic spiking and then to bursting, followed by a depolarization block at very high levels of $\left[\mathrm{K}^{+}\right]$, thus mimicking a seizure-like response (Filatov et al. 2011). Compared to controls, mutant slices exhibited a narrow range of hypersynchronous bursting and an elevated mean baseline measured from the integrated trace, especially from $8 \mathrm{mM}$ to $12 \mathrm{mM}\left[\mathrm{K}^{+}\right]$(Figure 2B,C; Figure 2 - figure supplement 2A). Mutant slices also showed significantly enhanced relative peak amplitudes (at 8-9 $\mathrm{mM}\left[\mathrm{K}^{+}\right]$; Figure 2 - figure supplement $2 \mathrm{~B}$ ). Thus, the mutation lowers the excitability threshold and a depolarization block is reached faster than in controls. Further, acute extracellular application of BKM120 suppressed the hypersynchronous ictal bursts in the mutant CA1 field in 20-30 min, with 
130 minimal physiological effect on control brains (Figure 2D,E). These data provide evidence of a Pik3ca-driven active mechanism.

\section{Mutant CA1 and CA3 pyramidal neurons are hyperexcitable}

Next, we investigated mechanisms driving the mutant epileptiform activity at the cellular level, using whole-cell patch-clamp recordings from CA1 and CA3 pyramidal neurons in P16-20 control and mutant brains (Figure 3A). Silent and spontaneously

137 firing, tonic and burst-generating neurons were detected in both control and mutant slices (Figure 3B,C). However, mutant slices had a significantly higher proportion of CA1 compared to controls (Figure 3D,E). Additionally, we observed significantly higher tonic spike frequencies in mutant CA1 and CA3 and higher burst frequency in mutant CA1, compared to controls (Figure 3F,G). Burst-generating cells demonstrated multiple burst types. Specifically, we identified burst clusters and two types of plateau-bursts:

144 paroxysmal depolarization shift (PDS) and non-PDS waveforms (Figure 3 - figure supplement 1A). We defined burst cluster as a multi-spike burst activity of random nature without a plateau potential; these were only observed in mutant slices (Figure 3 -

147 figure supplement 1B). Plateau-bursts with depolarization shift resulting in sodium-spike 148 inactivation were termed as PDS "bursting cells". These depolarization shifts have 149 previously been implicated as the intracellular correlate of in vivo interictal spikes 150 (Marcuccilli et al. 2010; McCormick and Contreras 2001; Kubista, Boehm, and Hotka

151 2019; Tryba et al. 2019). We defined non-PDS bursts as those where plateau potential 152 developed in absence of prominent sodium-spike inactivation. No significant differences 
153 between control and mutant hippocampal pyramidal cells were observed with respect to average burst duration or inter-burst interval (Figure 3 - figure supplement $1 \mathrm{C}-\mathrm{E}$ ). However, the plateau potential shift (PPS), defined here as the difference of the steady state plateau potential and the resting membrane potential (RMP), was significantly

157 larger in mutant CA1 but not in CA3, relative to respective controls (Figure $3 \mathrm{H}, \mathrm{H}^{\prime}$ ). This was despite similar RMP across control and mutant hippocampal neurons (Figure 3 figure supplement $2 \mathrm{~A}-\mathrm{C}$ ). The evoked current-clamp recordings further validated the spontaneous activity results, especially by displaying significantly higher percentage of burst-generating pyramidal neurons in the mutant hippocampus (Figure 3I-M). resistance, rheobase current and burst-threshold current, as well as evoked tonic spike frequencies (for the tested 0-90pA range), was observed between control and mutant

165 cells (Table 1; Figure 3 - figure supplement 2D-F). But the decay time constant for mutant CA3 neurons was significantly longer than that in mutant CA1 and control

167 groups (Table 1). With similar resistance, this implied that mutant CA3 neurons have higher membrane capacitance than other cell groups. Together, these data demonstrate that Pik3ca overactivation results in intracellular hyperexcitability, with some distinct cell type-specific effects.

172 synaptic interactions or other intrinsic properties, we assessed the effects of channel 173 and receptor blockers on mutant hippocampal physiology. Blocking glutamatergic inputs

174 by extracellular administration of NMDA and non-NMDA receptor-antagonists, 3-(( \pm$) 2-$ 175 carboxypiperazin-4yl) propyl-1-phosphate (CPP) and 6-cyano-7-nitroquinoxaline-2,3- 
176 dione (CNQX) respectively, had no overt physiological effect on the majority of mutant

177 hippocampal neurons (Figure 4 - figure supplement 1A-C,E,F,H-K). Similarly, blocking

178 inhibitory synaptic inputs with gabazine did not significantly alter the mutant firing

179 patterns, spike frequencies or PPS (Figure 4 - figure supplement 1A,D,G,L). The

proportion of mutant CA1 neurons affected by these channel blockers was

181 comparatively less than that in CA3. Our data lead to the important conclusion that

182 Pik3ca-driven epileptiform activity is primarily not dependent on synaptic transmission.

183 In contrast, inhibition of calcium $\left(\mathrm{Ca}^{2+}\right)$-dependent inward current by extracellular cadmium $\left(\mathrm{Cd}^{2+}\right)$ attenuated the paroxysmal bursts and reduced burst frequency and PPS (Figure 4A-D), indicating a calcium channel-dependent mechanism underlying the Pik3ca-dependent epileptiform activity. Intracellular cesium blocked potassium channels and related currents, altering the intrinsic firing pattern in both control and mutant hippocampal slices. Specifically, compared to regular baseline recordings, intracellular cesium considerably reduced the proportion of tonic-firing cells in both CA1 and CA3 (Figure 4E-H, compare to Figure 3D,E). Unlike the spontaneous recordings, intracellular cesium prompted the burst frequency in mutant CA1 to normalize and in mutant CA3 to

192 significantly rise, relative to respective controls (Figure 4I, compare to Figure 3G).

193 Intracellular cesium also normalized the mutant PPS to control levels (Figure 4J,

194 compare to Figure $3 \mathrm{H}$ ). No overt effect on RMP or input resistance was seen in cesium-

195 treated control and mutant cells (Figure 4K,L). We conclude that Pik3ca-related 


\section{Acute treatment of epileptiform activity with PI3K pathway drugs}

The acute suppression of epileptiform activity in Nestin-cre;Pik3ca ${ }^{5545 K}$ mice by BKM120, both in vivo (Roy et al. 2015) and at the tissue level, prompted us to dissect the downstream pathway dynamics using inhibitors at the cellular level, in order to coarsely determine their mechanistic roles and identify new therapeutic targets to treat intractable epilepsy (Figure 5A). Acute extracellular administration of BKM120 or the pan-AKT inhibitor AZD5363 (Davies et al. 2012) resulted in a large-scale and significant alteration of firing pattern, frequencies and a relative reduction of PPS, sometimes leading to gradual silencing of the recorded neurons (Figure 5B-I,I'). Neither drug had any significant effect on neuronal RMP or tonic rheobase current (Figure 5 - figure supplement $1 \mathrm{~A}, \mathrm{~B}, \mathrm{E}, \mathrm{F})$. In contrast to BKM120, acute AKT downregulation by AZD5363 significantly reduced the mutant burst duration and inter-burst interval (Figure 5 - figure supplement 1C,D,G,H). Further, AZD5363 altered the physiology of all mutant CA3 neurons much faster ( $\sim 8 \mathrm{~min})$ than BKM120 ( $\sim 32 \mathrm{~min})$; however, both drugs changed the intracellular activity of $\sim 50 \%$ cells within 4 min (Figure 5 - figure supplement $1 \mathrm{l}, \mathrm{J}$ ). AZD5363 also blocked spontaneous bursts in mutant neurons faster than BKM120 (Figure 5 - figure supplement $1 \mathrm{~K}$ ). Thus, acute regulation of both PI3K and AKT activity directly suppressed Pik3caE545K-driven epileptiform neuronal activity. In contrast, acute administration of the MTOR inhibitor RAD001 (everolimus) (Cho 2011; Krueger et al. 2010) showed no overt effect on the mutant RMP, tonic or burst firing patterns, frequencies, average PPS, burst duration, inter-burst interval and rheobase current (Figure 5J-M, Figure 5 - figure supplement 2A-D). This was despite western blot confirmation that acute treatment of forebrain slices with RAD001 modulated direct 
222 downstream targets of MTOR (Figure 5 - figure supplement 2E-G). In summary, our

223 study demonstrates that epileptiform activity caused by Pik3ca overactivation is based

224 on multiple intrinsic electrophysiological characteristics that are acutely modifiable by

225 downregulating PI3K and AKT activity, but not MTOR. 


\section{DISCUSSION}

Activating mutations in the PI3K-AKT-MTOR pathway commonly cause pediatric intractable epilepsy (Kim and Lee 2019; Dobyns and Mirzaa 2019); yet the underlying mechanisms remain largely undefined. Using our Nestin-cre;Pik3caE545K model, we now establish that Pik3ca-dependent neuronal hyperexcitability in hippocampal pyramidal neurons is driven primarily by intrinsic neuronal mechanisms. Acute attenuation of epileptiform activity by inhibiting AKT but not MTOR also reveals a previously unknown role of PI3K signaling in neuronal homeostasis. Our mouse model of human intractable epilepsy is now validated across whole animal, tissue, and cellular levels.

Epileptiform activity is typically marked by increased tonic depolarizations and/or quasiperiodic bursts, mediated by intrinsic membrane properties, ephaptic or synaptic/circuit-level interactions (McCormick and Contreras 2001; Dudek, Yasumura, and Rash 1998). We confirmed enhanced interictal spike frequency and diverse, synchronized epileptiform spike patterns in the mutant brains in vivo, predominantly in the hippocampus. This is consistent with studies of PIK3CA variants in brain tumors and mouse models with patient-related Pik3r2 mutations, which are less common causes of intractable epilepsy (Yu et al. 2020; Shi et al. 2020). Our in vitro analyses revealed intracellular correlates of epileptiform activity and enhanced firing frequencies in the mutant hippocampal pyramidal neurons. Relative to controls, Pik3caE545K neurons exhibited significantly higher proportions of bursting cells and higher heterogeneity in burst patterns, including burst clusters and PDSs. A prior study showed that human neurons from surgically resected neocortical samples of pediatric patients with focal cortical dysplasia (FCD) exhibited remarkably similar burst characteristics (Marcuccilli et 
al. 2010). These samples were not genotyped; however, since most cases of FCD and epilepsy result from variants in PI3K pathway genes (Mirzaa 2018), such cross-species phenotypic correlation is remarkable and emphasizes the clinical relevance of our mouse model. neuronal plasticity (Sanchez-Alegria et al. 2018). For example, neocortical samples from patient and mouse models with TSC mutations exhibit synaptic input-mediated epileptogenic hyperexcitability (Wang et al. 2007). However, blocking glutamatergic (NMDA and non-NMDA) or GABAergic synaptic inputs showed no significant effect on the neuronal activity in our mutant brain slices. We acknowledge that altered neuronal

259 circuitry may be relevant to Pik3ca-mediated epilepsy, but our data demonstrate that altered synaptic interactions are at least not primary mediators of dynamic hippocampal neuronal hyperexcitability. driven epileptiform activity is predominantly mediated by multiple altered cell-intrinsic properties. Yet, some cell-intrinsic properties, such as burst frequencies, PPS and time

266 constants, are distinctly different between mutant CA1 and CA3 neurons. Since all

267 neurons do not react uniformly to either pathway overactivation or $\mathrm{Cd}^{2+} / \mathrm{Cs}^{+}$-dependent 268 channel inhibition, current anti-seizure drugs that typically target single ion channels cannot address the heterogeneous dysregulation, thus potentially explaining epileptic intractability in this patient population. It is intriguing to note that intercellular signaling

271 heterogeneity involving PI3K-AKT-MTOR pathway was also reported by a recent 
272 quantitative study that highlighted its potential relevance to human disorders, such as

273 insulin resistance (Norris et al. 2021).

PI3K-AKT-MTOR inhibitors developed to treat cancer potentially represent novel

275 anti-seizure therapeutics (Cardamone et al. 2014; Lindhurst et al. 2015; Maira et al.

276 2012; Zou et al. 2020; Forde et al. 2021; Venot et al. 2018). Rapamycin and its analogs,

277 that are currently in clinical use to treat epilepsy in TSC patients, curbed epileptiform

278 activity in mouse models harboring TSC1/2, RHEB, MTOR or PTEN mutations when

279 administered long-term (>7-day) (Curatolo and Moavero 2013; Crino 2016; Lasarge and

280 Danzer 2014; Stafstrom 2019; Kim and Lee 2019). In contrast, we show acute inhibition

281 of epileptiform activity by BKM120 in vitro, confirming our previous in vivo finding (Roy

et al. 2015). We also demonstrate that acute AKT inhibition with AZD5363 has similar

effects. This first preclinical study using AZD5363 to treat epilepsy shows that acute

284 Pik3ca-driven epileptiform mechanism is predominantly AKT-dependent, limiting roles

285 for other PI3K targets. Intriguingly, rapamycin analog RAD001 had minimal acute effect

286 in our model. While elevated MTOR activity is known to be epileptogenic (Crino 2016;

287 Kim and Lee 2019), our data suggest that alternate PI3K-AKT targets acutely regulate

288 neuronal hyperexcitability. This study establishes an important foundation to determine

289 active pathway-driven cellular mechanisms and to assess the plethora of available PI3K

290 pathway inhibitors, facilitating new molecularly rational therapeutic interventions for

291 intractable epilepsy. 


\section{MATERIALS AND METHODS}

\section{Mice}

294 The following mouse lines were used: Nestin-cre (Jackson Labs, Bar Harbor, Maine, 295 USA; Stock \#003771, RRID: IMSR_JAX:003771), conditional Pik3caE545K knock-in 296 (Robinson et al. 2012). Nestin-cre and Pik3ca ${ }^{E 545 K}$ mouse lines were maintained in 297 C57BL/6 and FVB backgrounds respectively. We have designated Nestincre;Pik3ca ${ }^{E 545 K}$ conditional mutant mice as "Pik3ca mutants" or "mutants" throughout the manuscript.

All mice were housed in Optimice cages with aspen bedding at the Seattle Children's Research Institute's specific pathogen-free (SPF) vivarium facility (light "ON": $6 a m-8 p m)$. Noon of the day of vaginal plug was designated as embryonic day 0.5 (E0.5). The day of birth was designated as postnatal day 0 (P0). Genotyping by PCR was done using separate sets of primers for the Cre coding region and the Pik3caE545K allele, as previously described(Roy et al. 2015). All mouse procedures were approved and conducted in accordance with the guidelines laid down by the Institutional Animal Care and Use Committees (IACUC) of Seattle Children's Research Institute, Seattle, WA, USA. ARRIVE guidelines have been followed for reporting work involving animal research.

\section{In vivo electrophysiology}

3125 control and 6 Nestin-cre;Pik3ca ${ }^{E 545 K}$ mutant mice (age: $\sim P 70$ ) were used for in vivo 313 regular and depth-electrode electrophysiology experiments. We saw no sex-dependent 314 data correlation (Roy et al. 2015). 
315 Electrode implantation surgery: Mice underwent survival surgery to implant ECoG,

316 EMG, and hippocampal depth electrodes under isoflurane anesthesia using similar

317 procedures as reported in our prior work (Bolea et al. 2019; Roy et al. 2015). The ECoG

318 electrodes consisted of silver wire (diameter: $130 \mu \mathrm{m}$ bare; $180 \mu \mathrm{m}$ coated) attached to

319 micro screws. The ECoG electrodes were implanted bilaterally through small cranial

320 burr holes above the somatosensory cortices. A similar reference electrode was placed

321 above the cerebellum following the same procedure. The depth electrodes were made

322 of 2 fine twisted tungsten wires (30um nylon coated, California fine wire) and implanted

323 in the hippocampal CA1 region (coordinates: $-2.0 \mathrm{~mm}$ anteroposterior, $1.5 \mathrm{~mm}$

324 mediolateral, $1.9 \mathrm{~mm}$ dorsoventral in reference to bregma) to record local field potential

325 (LFP). All electrodes were connected to interface connector and fixed to the skull with

326 dental cement (Lang Dental Manufacturing Co., Inc., Wheeling, IL). Mice were allowed

327 to recover from surgery for 2-3 days.

Video, electroencephalagraphy and local field potential (Video-EEG-LFP) recording:

329 Simultaneous video-EEG-LFP recordings were collected from conscious mice on

330 PowerLab 8/35 and 16/30 data acquisition units, using LabChart 7.3.3 software (AD

331 Instruments, Colorado Spring, USA). 6 hours of baseline ECoG tracings were visually

332 reviewed for the presence of spontaneous epileptiform events, as previously studied

333 (Kalume 2013; Liautard et al. 2013; Roy et al. 2015). All bioelectrical signals were

334 acquired at a $20 \mathrm{KHz}$ sampling rate. The ECoG signals were processed with a 1-70 $\mathrm{Hz}$

335 bandpass filter and the LFP signal with a $5 \mathrm{~Hz}$ high-pass filter. Interictal spikes were 336 identified as transient, clearly distinguished from background activity, with pointed peak

337 and slow wave. Myoclonic seizures were identified as shock-like muscular jerks on 
338 video, associated with a spike or polyspike-wave complex on EEG. Power spectral analysis and visual inspection of the data were conducted to characterize the EEG activity in different frequency bands and identify epileptiform event on the ECoG and local CA1 field recordings using the Labchart 8.2 software.

\section{In vitro electrophysiology}

344 Slice preparation: Postnatal (P16-20) pups were anesthetized briefly in a closed

345 chamber by administering isoflurane (5\% flow rate) or $\mathrm{CO}_{2}$ (constant flow rate: $10-30 \%$ of chamber vol/min); then perfused transcardially with ice-cold low Na+-buffer ("slicing solution," which included the following: $252 \mathrm{mM}$ sucrose, $2 \mathrm{mM} \mathrm{KCl,} 2 \mathrm{mM} \mathrm{MgCl}, 2.6$ $\mathrm{mM} \mathrm{CaCl}_{2}, 1.2 \mathrm{mM} \mathrm{NaH}_{2} \mathrm{PO}_{4}, 26 \mathrm{mM} \mathrm{NaHCO}_{3}$, and $15 \mathrm{mM}$ glucose, with the $\mathrm{pH}$ adjusted to 7.4 and the osmolarity to $310 \pm 5 \mathrm{mOsm})$. Brain was dissected out by separating the head and cutting along the skull sutures using fine scissors and forceps.

351 The forebrain was isolated in ice-cold, oxygenated $\left(95 \% \mathrm{O}_{2}, 5 \% \mathrm{CO}_{2}\right)$ slicing solution. A 352 slanted $\left(\sim 15^{\circ}\right.$ from vertical) agar block was secured on a specimen tray as a support for 353 the brain during slicing. The isolated forebrain was glued with cyanoacrylate in the 354 orientation depending on the type of slices we wanted; and then placed in the vibratome 355 for slicing. Slicing was proceeded until hippocampal landmark was visible. For coronal 356 slices (extracellular recordings), the forebrain was placed such that its antero-posterior 357 (A-P) axis was perpendicular to the specimen tray/vibratome blade, and olfactory bulb 358 distal to the tray surface. For horizontal slices (whole-cell recordings), the forebrain was oriented such that it's A-P axis was parallel to the specimen tray and ventral side 360 (hippocampal side) was on the top, distal to the tray surface. Once the hippocampus 
361 became visible, thick, acute slices (thickness: $350 \mu \mathrm{m}$ for extracellular recordings, 200-

362

363

364

365

366

367

368

369

370

371

372

373

374

375

376

377

378

379

380

381

382

383

250 $\mu \mathrm{m}$ for whole-cell patch clamp recordings) were taken and incubated in ice-cold

slicing solution continuously oxygenated with $95 \% \mathrm{O}_{2} / 5 \% \mathrm{CO}_{2}$. After cutting, slices were immediately returned to the same solution and maintained in a warm bath $\left(28 \pm 0.5^{\circ} \mathrm{C}\right)$

for recovery. After $30 \mathrm{~min}$, they were transferred into regular artificial cerebrospinal fluid (aCSF), composed of the same components as slicing solution except for the

replacement of sucrose with $126 \mathrm{mM} \mathrm{NaCl}$. Slices were then kept at room temperature, continuously superfused with oxygenated aCSF, until recording. Given that Pik3caE545K mutant is megalencephalic, a greater number of hippocampal/forebrain sections were obtained. However, care was taken so that the dorso-ventral plane(s) used for recording was always comparable between control and mutant slices. No randomization was used. Tissue collection was not performed blind since the mice were subjected to genotyping and drug administration.

Recording: Slices were transferred into a recording chamber, continuously superfused with oxygenated aCSF, for extracellular or intracellular whole-cell recordings. The pClamp software suite (Molecular Devices; RRID:SCR_011323) was used for data acquisition and analysis. Signals were amplified (MultiClamp 700A, Axon Instruments, Molecular Devices, USA), digitized (D1322A, Axon Instruments, Molecular Devices, USA), and stored in a computer for post-hoc analysis.

a) Extracellular recording: To determine if hippocampal neuronal populations in Pik3caE545K mutants have different electrochemical signatures than controls, extracellular population recordings were performed on CA1 hippocampal pyramidal neuronal layer in acute $350 \mu \mathrm{m}$-thick coronal brain slices of $\sim \mathrm{P} 16-20$ Pik3caE545K mutant 
384 and control littermates $(n=6)$. To induce epileptiform activity in the slices, we increased

385 potassium concentration $\left(\left[\mathrm{K}^{+}\right]\right)$(Borck and Jefferys 1999; Leschinger et al. 1993) from 3

$\mathrm{mM}$ to $12 \mathrm{mM}$, in $1 \mathrm{mM}$ increments at $30^{\circ} \mathrm{C}$. This standard model induces wild-type

neurons to transition from a silent neuronal state to tonic spiking and then to bursting, followed by depolarization block at very high [K+] (Filatov et al. 2011).

b) Intracellular recording: Horizontal hemi-forebrain slices with prominent

hippocampus were used for intracellular whole-cell visual patch-clamp experiments.

Slices transferred to the recording chamber were maintained at $30-34^{\circ} \mathrm{C}$, constantly

403 CA1 and CA3 respectively. Following intracellular recording protocols were also used:

404 i. Spontaneous gap-free recordings in current (I)-clamp: cells were typically tested 405 at resting conditions (without current injection) unless noticed otherwise. 
406 ii. Evoked I-clamp steps protocol: current steps start at -50 pA, incremental 10 pA,

407 duration; $300 \mathrm{~ms} ; 15$ steps $(-90$ to $+50 \mathrm{pA})$ were recorded across experiments.

\section{Acute chemical assays}

Channel blockers: Chemicals inhibiting specific ion channels were introduced in the

411 bath/recording chamber during in vitro whole-cell recordings to compare different

412 components contributing to the neural activity in control and Pik3caE545K mutant mice. To

413 block all fast-synaptic excitatory transmission, 3-((土)2-carboxypiperazin-4yl) propyl-1-

414 phosphate (CPP, NMDA receptor antagonist, $20 \mu \mathrm{M}$; Tocris Bioscience, UK) and 6-

415 cyano-7-nitroquinoxaline-2,3-dione (CNQX, AMPA/kainite (non-NMDA) receptor

416 antagonist, $20 \mu \mathrm{M}$, diluted in DMSO; Alomone Labs, Israel) were introduced in the bath

417 (Lehmann et al. 1987; Lester et al. 1989). SR95531 hydrobromide (Gabazine, GABAA

418 receptor antagonist, $10 \mu \mathrm{M}$, Tocris Bioscience, UK) were used to block inhibitory

419 synaptic transmission. Divalent cation $\mathrm{Cd}^{2+}\left(\mathrm{CdCl}_{2}, 100 \mu \mathrm{M}\right.$; Sigma-Aldrich, USA)

420 (Boissard et al. 2002) was used to depress synaptic transmission and block inward

421 calcium-selective current, isolating the outward $\mathrm{K}^{+}$current. To block voltage-dependent

$422 \mathrm{~K}^{+}$channels, intracellular administration of cesium (Covey, Kauer, and Casseday 1996)

423 was done by replacing potassium gluconate with cesium gluconate in the internal

424 solution while maintaining the same osmolarity.

425 PI3K pathway drugs: Drugs regulating PI3K pathway were added to the circulating

426 recording buffer, thus getting acutely administered in the brain slice placed in the

427 recording chamber. For protein analyses, these were added at identical concentration to

428 the brain slices incubated in oxygenated aCSF for $\sim 1 \mathrm{hr}$. The following PI3K pathway 
429 inhibitors were dissolved in 100\% DMSO and used in vitro: pan-PI3K inhibitor BKM120

430 (Buparlisib; Novartis, Switzerland; working concentration: $3.5 \mu \mathrm{M}$ ); pan-AKT inhibitor

431 AZD5363 (Capivasertib; Selleckchem, USA; working concentration: $0.5 \mu \mathrm{M}$ ); MTOR

432 inhibitor RAD001 (Everolimus, Chem Express Cat\# 159351-69-6; working

433 concentration: $0.52 \mu \mathrm{M})$.

434

\section{Western blotting}

436 Horizontal forebrain slices from 5 control and 5 mutant mice were obtained and recovered in oxygenated aCSF as detailed above. Slices showing nice hippocampal morphology were selected, treated for 1 hour with DMSO, BKM120, AZD5363 and RAD001 respectively, in the same concentrations used for recording. The treated slices were then flash-frozen in liquid nitrogen and stored at $-80^{\circ} \mathrm{C}$ for post-processing. These

441 brain slices were lysed in NP-40 lysis buffer (150 mM NaCl, 50 mM Tris (pH 7.4), 1\%

442 NP-40, $10 \mathrm{mM} \mathrm{NaF}, 2 \mathrm{mM}$ sodium orthovanadate + protease/phosphatase inhibitor

443 cocktails [Sigma, USA]). Samples were normalized to equal protein concentrations

$444(0.333 \mathrm{mg} / \mathrm{ml})$ using Pierce BCA protein assay (Thermo Fisher Scientific, USA).

445 Standards were made through serial dilutions of $10 \mathrm{mg} / \mathrm{ml} \mathrm{BSA}$. Samples were diluted

446 into a final concentration of $1 \times$ Laemmli sample buffer and boiled at $95^{\circ} \mathrm{C}$ for ten

447 minutes. 7.5\% 10-well gels were prepared, and samples were run at $120 \mathrm{~V}$ for 1.5 hours.

448 Gels were transferred onto polyvinylidene difluoride (Millipore) membranes and run 449 either overnight at $25 \mathrm{~V}$ or for 2 hours at $60 \mathrm{~V}$. Membranes were blocked in $4 \%$ milk in

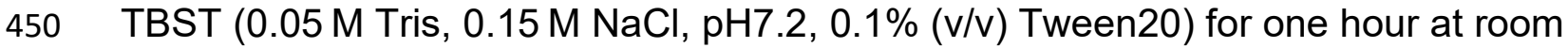
451 temperature, and primary antibodies were applied overnight at $4^{\circ} \mathrm{C}$ in blocking medium. 
452 Primary antibodies for western blots were diluted as follows: rabbit anti-Phospho-AKT

453 Ser473 (D9E) (Cell Signaling Technology, USA; RRID: AB_2797780; 1:2000), mouse

454 anti-Pan-AKT (40D4) (Cell Signaling Technology, USA; Cat\# 2920; $1: 2000)$, rabbit anti-

455 Phospho-S6 Ribosomal Protein Ser235/236 (Cell Signaling Technology, USA; RRID:

456 AB_2721245, 1:2000), mouse anti-S6 Ribosomal Protein (54D2) (Cell Signaling

457 Technology, USA; RRID: AB_2238583, 1:1000), rabbit anti-beta(b)-Actin (GeneTex,

458 USA; RRID: AB_1949572, 1:10000). After washing and probing respectively with goat

459 anti-rabbit (RRID: AB_2313567) and anti-mouse (RRID: AB_10015289) horseradish

460 peroxidase (HRP)-conjugated secondary antibodies (1:10000; Jackson

461 ImmunoResearch Labs, USA), blots were imaged using Femto chemiluminescent

462 detection reagents (Thermo Fisher Scientific, USA; Cat\# 34095) in a FluorChem R

463 western blot imaging system (ProteinSimple, Bio-Techne, USA). 8-bit images were used

464 as a representative western blot. 16-bit images were used to quantify the intensity of

465 each band using ImageJ v1.53. Regions of interest were drawn in each sample's lane.

466 After quantifying the lane in a histogram, the peak representing the band of interest was

467 isolated and the area of the region was measured as the band's quantification.

469 Quantitative and Statistical Analyses

$470 \quad$ Number of mice used was consistent with previous experiments completed and

471 published by us and other investigators. For extracellular field potential analyses,

472 baseline potential from integrated traces were measured for each $\left[\mathrm{K}^{+}\right]$and normalized to

473 the value at $3 \mathrm{mM}$ for each slice per genotype; relative peak amplitude was similarly

474 measured for control and mutant slices for 3,7,8,9 mM of [K+ ${ }^{+}$. In whole-cell patch-clamp 
475 recording, plateau potential shift (PPS) was calculated by subtracting the baseline 476 potential from the highest plateau/burst potential in a paroxysmal depolarizing event.

477 Burst duration and inter-burst interval were measured as shown in Figure 3 - figure

478 supplement 1 and averaged across multiple bursts per cell. Input resistance was

479 measured from evoked current-clamp recordings by dividing the voltage difference

480 (measured at -10pA to -30pA l-steps) by the current interval (20pA). The decay

481 membrane time constant was obtained by recording the membrane response to 20pA

482 hyperpolarizing current pulses (300 ms duration, $1 \mathrm{~Hz}$ ) and fitting the response to a

483

484

485

486

487

488

489

490

491

492

493

494

495

496

497 single exponential curve. We chose $20 \mathrm{pA}$ of hyperpolarizing current because such a current intensity did not produce sag. Evoked spike frequencies and rheobase current were calculated exclusively from tonic-firing cells. Burst threshold current was calculated from burst-generating cells as the first current step which induced burst. In vitro electrophysiological analyses were performed using Clampfit 10.7 and 11 (pClamp, Molecular Devices, USA). For Western Blots, each band intensity was recalculated relative to its respective b-actin band intensity, and then normalized across average intensity per protein lane. Normalized ratios of phosphoproteins over total proteins were thereafter obtained.

Statistical significance was assessed using 2-tailed unpaired t-tests with Welch's correction (EEG power analyses, whole-cell RMP, burst duration, inter-burst interval, $\mathrm{Cd}^{2+}$ data), 2-tailed paired t-tests (field potential baseline measurement, rheobase current, drug-treated analyses) and ANOVA followed by Tukey post-tests (EEG interictal spike frequency, field potential relative peak amplitude; whole-cell tonic spike and burst frequencies, cell proportions, PPS, evoked spike frequency and time 
constant; Western blots). Normal distribution was assumed for the data analyses, when required. For EEG-ECoG-LFP experiments, quantitative and statistical data analysis was performed in Labchart 8.2 software (AD Instruments, Colorado Spring, USA) and Igor Pro 6.37 (WaveMetrics Inc., USA); final graphs were made in GraphPad Prism v7.0 (GraphPad Software Inc., San Diego, USA). For the remaining data, statistical analyses and graph plotting were done using GraphPad Prism v7.0 and Microsoft Excel. Differences were considered significant at $p<0.05$.

\section{Acknowledgments}

We thank Suzanne J. Baker for gifts of mouse lines (Nestin-cre and Pik3caE545K); Leon Murphy (Novartis) for BKM120; Rory M. Murphy, Amanda P. Tran Hartman, Nikhil Sahai and Jiyun Ryu for technical assistance; Aguan D. Wei and Paul Wakenight for discussions. This work is funded by the NIH grants 1R01NS099027 (K.J.M.), R01MH113545 (S.E.P.S.), R01NS102796 (F.K.), and CURE Sleep and Epilepsy Grant (F.K.).

Author Contributions: A.R., F.K., J.M.R. and K.J.M. contributed to the study conception and design. A.R., V.H., A.M.B., D.T.W. and F.K. contributed to the data collection. A.R. and F.K. contributed to in vitro and in vivo data analyses respectively. D.T.W. and S.E.P.S. contributed to Western blot data analyses and interpretation. A.R., F.K., J.M.R., K.J.M. contributed to the overall data interpretation. S.E.P.S., F.K. and K.J.M. provided the funding resources. A.R. wrote the first draft of the manuscript and 
521 others commented on previous versions of the manuscript. All authors read and

522 approved the final manuscript.

523

\section{Ethics}

525 Animal experimentation: All animal experimentation was conducted in accordance with

526 the guidelines laid down by the Institutional Animal Care and Use Committees (IACUC)

527 of Seattle Children's Research Institute, Seattle, WA, USA (protocol IDs: IACUC00006

528 (K.J.M.); IACUC00108 (F.K.)). 


\section{REFERENCES}

Barker-Haliski, M., and H.S. White. 2019. 'Validated animal models for antiseizure drug (ASD) discovery: Advantages and potential pitfalls in ASD screening', Neuropharmacology: 107750.

Bast, T., G. Ramantani, A. Seitz, and D. Rating. 2006. 'Focal cortical dysplasia: prevalence, clinical presentation and epilepsy in children and adults', Acta Neurol Scand, 113: 72-81.

Berdichevsky, Y., A. M. Dryer, Y. Saponjian, M. M. Mahoney, C. A. Pimentel, C. A. Lucini, M. Usenovic, and K. J. Staley. 2013. 'PI3K-Akt signaling activates mTOR-mediated epileptogenesis in organotypic hippocampal culture model of post-traumatic epilepsy', J Neurosci, 33: 9056-67.

Blumcke, I., M. Thom, E. Aronica, D. D. Armstrong, H. V. Vinters, A. Palmini, T. S. Jacques, G. Avanzini, A. J. Barkovich, G. Battaglia, A. Becker, C. Cepeda, F. Cendes, N. Colombo, P. Crino, J. H. Cross, O. Delalande, F. Dubeau, J. Duncan, R. Guerrini, P. Kahane, G. Mathern, I. Najm, C. Ozkara, C. Raybaud, A. Represa, S. N. Roper, N. Salamon, A. Schulze-Bonhage, L. Tassi, A. Vezzani, and R. Spreafico. 2011. 'The clinicopathologic spectrum of focal cortical dysplasias: a consensus classification proposed by an ad hoc Task Force of the ILAE Diagnostic Methods Commission', Epilepsia, 52: 158-74.

Boissard, R., D. Gervasoni, M. H. Schmidt, B. Barbagli, P. Fort, and P. H. Luppi. 2002. 'The rat pontomedullary network responsible for paradoxical sleep onset and maintenance: a combined microinjection and functional neuroanatomical study', Eur J Neurosci, 16: 1959-73.

Bolea, I., A. Gella, E. Sanz, P. Prada-Dacasa, F. Menardy, A. M. Bard, P. Machuca-Marquez, A. ErasoPichot, G. Modol-Caballero, X. Navarro, F. Kalume, and A. Quintana. 2019. 'Defined neuronal populations drive fatal phenotype in a mouse model of Leigh syndrome', Elife, 8.

Borck, C., and J. G. Jefferys. 1999. 'Seizure-like events in disinhibited ventral slices of adult rat hippocampus', J Neurophysiol, 82: 2130-42.

Cardamone, M., D. Flanagan, D. Mowat, S. E. Kennedy, M. Chopra, and J. A. Lawson. 2014. 'Mammalian target of rapamycin inhibitors for intractable epilepsy and subependymal giant cell astrocytomas in tuberous sclerosis complex', J Pediatr, 164: 1195-200.

Chatzikonstantinou, A. 2014. 'Epilepsy and the hippocampus', Front Neurol Neurosci, 34: 121-42.

Cho, C. H. 2011. 'Frontier of epilepsy research - mTOR signaling pathway', Exp Mol Med, 43: 231-74.

Covey, E., J. A. Kauer, and J. H. Casseday. 1996. 'Whole-cell patch-clamp recording reveals subthreshold sound-evoked postsynaptic currents in the inferior colliculus of awake bats', J Neurosci, 16: 3009-18.

Crino, P. B. 2016. 'The mTOR signalling cascade: paving new roads to cure neurological disease', Nat Rev Neurol, 12: 379-92.

Curatolo, P., and R. Moavero. 2013. 'mTOR inhibitors as a new therapeutic option for epilepsy', Expert Rev Neurother, 13: 627-38.

Davies, B. R., H. Greenwood, P. Dudley, C. Crafter, D. H. Yu, J. Zhang, J. Li, B. Gao, Q. Ji, J. Maynard, S. A. Ricketts, D. Cross, S. Cosulich, C. C. Chresta, K. Page, J. Yates, C. Lane, R. Watson, R. Luke, D. Ogilvie, and M. Pass. 2012. 'Preclinical pharmacology of AZD5363, an inhibitor of AKT: pharmacodynamics, antitumor activity, and correlation of monotherapy activity with genetic background', Mol Cancer Ther, 11: 873-87.

Dobyns, W. B., and G. M. Mirzaa. 2019. 'Megalencephaly syndromes associated with mutations of core components of the PI3K-AKT-MTOR pathway: PIK3CA, PIK3R2, AKT3, and MTOR', Am J Med Genet C Semin Med Genet, 181: 582-90.

Dudek, F. E., T. Yasumura, and J. E. Rash. 1998. "Non-synaptic' mechanisms in seizures and epileptogenesis', Cell Biol Int, 22: 793-805.

Filatov, G., G. P. Krishnan, N. F. Rulkov, and M. Bazhenov. 2011. 'Dynamics of epileptiform activity in mouse hippocampal slices', J Biol Phys, 37: 347-60. 
Forde, K., N. Resta, C. Ranieri, D. Rea, O. Kubassova, M. Hinton, K. A. Andrews, R. Semple, A. D. Irvine, and V. Dvorakova. 2021. 'Clinical experience with the AKT1 inhibitor miransertib in two children with PIK3CA-related overgrowth syndrome', Orphanet J Rare Dis, 16: 109.

Hughes, J. R. 2008. 'Gamma, fast, and ultrafast waves of the brain: their relationships with epilepsy and behavior', Epilepsy Behav, 13: 25-31.

Kalume, F. 2013. 'Sudden unexpected death in Dravet syndrome: respiratory and other physiological dysfunctions', Respir Physiol Neurobiol, 189: 324-8.

Kehne, J. H., B. D. Klein, S. Raeissi, and S. Sharma. 2017. 'The National Institute of Neurological Disorders and Stroke (NINDS) Epilepsy Therapy Screening Program (ETSP)', Neurochem Res.

Kim, J. K., and J. H. Lee. 2019. 'Mechanistic Target of Rapamycin Pathway in Epileptic Disorders', J Korean Neurosurg Soc, 62: 272-87.

Krueger, D. A., M. M. Care, K. Holland, K. Agricola, C. Tudor, P. Mangeshkar, K. A. Wilson, A. Byars, T. Sahmoud, and D. N. Franz. 2010. 'Everolimus for subependymal giant-cell astrocytomas in tuberous sclerosis', N Engl J Med, 363: 1801-11.

Kubista, H., S. Boehm, and M. Hotka. 2019. 'The Paroxysmal Depolarization Shift: Reconsidering Its Role in Epilepsy, Epileptogenesis and Beyond', Int J Mol Sci, 20.

Lasarge, C. L., and S. C. Danzer. 2014. 'Mechanisms regulating neuronal excitability and seizure development following mTOR pathway hyperactivation', Front Mol Neurosci, 7: 18.

Lee, S. A., D. D. Spencer, and S. S. Spencer. 2000. 'Intracranial EEG seizure-onset patterns in neocortical epilepsy', Epilepsia, 41: 297-307.

Lehmann, J., J. Schneider, S. McPherson, D. E. Murphy, P. Bernard, C. Tsai, D. A. Bennett, G. Pastor, D. J. Steel, C. Boehm, and et al. 1987. 'CPP, a selective N-methyl-D-aspartate (NMDA)-type receptor antagonist: characterization in vitro and in vivo', J Pharmacol Exp Ther, 240: 737-46.

Leschinger, A., J. Stabel, P. Igelmund, and U. Heinemann. 1993. 'Pharmacological and electrographic properties of epileptiform activity induced by elevated $\mathrm{K}+$ and lowered $\mathrm{Ca} 2+$ and $\mathrm{Mg} 2+$ concentration in rat hippocampal slices', Exp Brain Res, 96: 230-40.

Lester, R. A., M. L. Quarum, J. D. Parker, E. Weber, and C. E. Jahr. 1989. 'Interaction of 6-cyano-7nitroquinoxaline-2,3-dione with the N-methyl-D-aspartate receptor-associated glycine binding site', Mol Pharmacol, 35: 565-70.

Liautard, C., P. Scalmani, G. Carriero, M. de Curtis, S. Franceschetti, and M. Mantegazza. 2013. 'Hippocampal hyperexcitability and specific epileptiform activity in a mouse model of Dravet syndrome', Epilepsia, 54: 1251-61.

Lindhurst, M. J., M. R. Yourick, Y. Yu, R. E. Savage, D. Ferrari, and L. G. Biesecker. 2015. 'Repression of AKT signaling by ARQ 092 in cells and tissues from patients with Proteus syndrome', Sci Rep, 5: 17162.

Madsen, R. R. 2020. 'PI3K in stemness regulation: from development to cancer', Biochem Soc Trans, 48: 301-15.

Maira, S. M., S. Pecchi, A. Huang, M. Burger, M. Knapp, D. Sterker, C. Schnell, D. Guthy, T. Nagel, M. Wiesmann, S. Brachmann, C. Fritsch, M. Dorsch, P. Chene, K. Shoemaker, A. De Pover, D. Menezes, G. Martiny-Baron, D. Fabbro, C. J. Wilson, R. Schlegel, F. Hofmann, C. GarciaEcheverria, W. R. Sellers, and C. F. Voliva. 2012. 'Identification and characterization of NVPBKM120, an orally available pan-class I PI3-kinase inhibitor', Mol Cancer Ther, 11: 317-28.

Marcuccilli, C. J., A. K. Tryba, W. van Drongelen, H. Koch, J. C. Viemari, F. Pena-Ortega, E. L. Doren, P. Pytel, M. Chevalier, A. Mrejeru, M. H. Kohrman, R. E. Lasky, S. M. Lew, D. M. Frim, and J. M. Ramirez. 2010. 'Neuronal bursting properties in focal and parafocal regions in pediatric neocortical epilepsy stratified by histology', J Clin Neurophysiol, 27: 387-97.

Mazumder, A. G., V. Patial, and D. Singh. 2019. 'Mycophenolate mofetil contributes to downregulation of the hippocampal interleukin type 2 and 1 beta mediated PI3K/AKT/mTOR pathway 
hyperactivation and attenuates neurobehavioral comorbidities in a rat model of temporal lobe epilepsy', Brain Behav Immun, 75: 84-93.

McCormick, D. A., and D. Contreras. 2001. 'On the cellular and network bases of epileptic seizures', Annu Rev Physiol, 63: 815-46.

Meng, X. F., J. T. Yu, J. H. Song, S. Chi, and L. Tan. 2013. 'Role of the mTOR signaling pathway in epilepsy', J Neurol Sci, 332: 4-15.

Mirzaa, G., Roy, A., Dobyns, W.B., Millen, K.J., Hevner, R.F. 2018. 'Hemimegalencephaly and Dysplastic Megalencephaly' ' in Golden JA Adle-Biassette H, Harding BN (ed.), Developmental Neuropathology (Wiley Blackwell).

Norris, D., P. Yang, S. Y. Shin, A. L. Kearney, H. J. Kim, T. Geddes, A. M. Senior, D. J. Fazakerley, L. K. Nguyen, D. E. James, and J. G. Burchfield. 2021. 'Signaling Heterogeneity is Defined by Pathway Architecture and Intercellular Variability in Protein Expression', iScience, 24: 102118.

Robinson, G., M. Parker, T. A. Kranenburg, C. Lu, X. Chen, L. Ding, T. N. Phoenix, E. Hedlund, L. Wei, X. Zhu, N. Chalhoub, S. J. Baker, R. Huether, R. Kriwacki, N. Curley, R. Thiruvenkatam, J. Wang, G. Wu, M. Rusch, X. Hong, J. Becksfort, P. Gupta, J. Ma, J. Easton, B. Vadodaria, A. Onar-Thomas, T. Lin, S. Li, S. Pounds, S. Paugh, D. Zhao, D. Kawauchi, M. F. Roussel, D. Finkelstein, D. W. Ellison, C. C. Lau, E. Bouffet, T. Hassall, S. Gururangan, R. Cohn, R. S. Fulton, L. L. Fulton, D. J. Dooling, K. Ochoa, A. Gajjar, E. R. Mardis, R. K. Wilson, J. R. Downing, J. Zhang, and R. J. Gilbertson. 2012. 'Novel mutations target distinct subgroups of medulloblastoma', Nature, 488: 43-8.

Roy, A., K. J. Millen, and R. P. Kapur. 2020. 'Hippocampal granule cell dispersion: a non-specific finding in pediatric patients with no history of seizures', Acta Neuropathol Commun, 8: 54.

Roy, A., R. M. Murphy, M. Deng, J. W. MacDonald, T. K. Bammler, K. A. Aldinger, I. A. Glass, and K. J. Millen. 2019. 'PI3K-Yap activity drives cortical gyrification and hydrocephalus in mice', Elife, 8.

Roy, A., J. Skibo, F. Kalume, J. Ni, S. Rankin, Y. Lu, W. B. Dobyns, G. B. Mills, J. J. Zhao, S. J. Baker, and K. J. Millen. 2015. 'Mouse models of human -related brain overgrowth have acutely treatable epilepsy', Elife, 4:e12703.

Sanchez-Alegria, K., M. Flores-Leon, E. Avila-Munoz, N. Rodriguez-Corona, and C. Arias. 2018. 'PI3K Signaling in Neurons: A Central Node for the Control of Multiple Functions', Int J Mol Sci, 19.

Shi, X., Y. Lim, A. K. Myers, B. L. Stallings, A. McCoy, J. Zeiger, J. Scheck, G. Cho, E. D. Marsh, G. M. Mirzaa, T. Tao, and J. A. Golden. 2020. 'PIK3R2/Pik3r2 Activating Mutations Result in Brain Overgrowth and EEG Changes', Ann Neurol, 88: 1077-94.

Stafstrom, C. E. 2019. Developmental Epilepsy - From Clinical Medicine to Neurobiological Mechanisms (World Scientific).

Stafstrom, C. E., and L. Carmant. 2015. 'Seizures and epilepsy: an overview for neuroscientists', Cold Spring Harb Perspect Med, 5.

Tryba, A. K., E. M. Merricks, S. Lee, T. Pham, S. Cho, D. R. Nordli, Jr., T. L. Eissa, R. R. Goodman, G. M. McKhann, Jr., R. G. Emerson, C. A. Schevon, and W. van Drongelen. 2019. 'Role of paroxysmal depolarization in focal seizure activity', J Neurophysiol, 122: 1861-73.

Venot, Q., T. Blanc, S. H. Rabia, L. Berteloot, S. Ladraa, J. P. Duong, E. Blanc, S. C. Johnson, C. Hoguin, O. Boccara, S. Sarnacki, N. Boddaert, S. Pannier, F. Martinez, S. Magassa, J. Yamaguchi, B. Knebelmann, P. Merville, N. Grenier, D. Joly, V. Cormier-Daire, C. Michot, C. Bole-Feysot, A. Picard, V. Soupre, S. Lyonnet, J. Sadoine, L. Slimani, C. Chaussain, C. Laroche-Raynaud, L. Guibaud, C. Broissand, J. Amiel, C. Legendre, F. Terzi, and G. Canaud. 2018. 'Targeted therapy in patients with PIK3CA-related overgrowth syndrome', Nature, 558: 540-46.

Wang, Y., J. S. Greenwood, M. E. Calcagnotto, H. E. Kirsch, N. M. Barbaro, and S. C. Baraban. 2007. 'Neocortical hyperexcitability in a human case of tuberous sclerosis complex and mice lacking neuronal expression of TSC1', Ann Neurol, 61: 139-52. 
671 Wilcox, K. S., P. J. West, and C. S. Metcalf. 2020. 'The current approach of the Epilepsy Therapy Screening Program contract site for identifying improved therapies for the treatment of pharmacoresistant seizures in epilepsy', Neuropharmacology, 166: 107811.

Yang, J., J. Nie, X. Ma, Y. Wei, Y. Peng, and X. Wei. 2019. 'Targeting PI3K in cancer: mechanisms and

675 advances in clinical trials', Mol Cancer, 18: 26.

676 Zhang, F. Chen, G. B. Mills, C. A. Mohila, C. J. Creighton, J. L. Noebels, K. L. Scott, and B. Deneen. 2020. 'PIK3CA variants selectively initiate brain hyperactivity during gliomagenesis', Nature, 578: 166-71.

681

Zou, Z., T. Tao, H. Li, and X. Zhu. 2020. 'mTOR signaling pathway and mTOR inhibitors in cancer: progress and challenges', Cell Biosci, 10: 31. 
TABLE

684 Table 1: Summary table of intrinsic membrane properties

685 Summary of basic intrinsic membrane properties quantitated and compared between

686 control and mutant CA1 and CA3 neurons. No significant differences in RMP, input

687 resistance and rheobase current (minimum injected current required to elicit the first

688 action potential) were observed between control and mutant neurons, in both CA1 and

689 CA3. Decay time constant of mutant CA3 neurons was significantly longer than that of

690 control CA1 $(p<0.0001)$ and CA3 $(p=0.0071)$ cells, as well as of mutant CA1 neurons

$691(p<0.0001)(F=31.21, d f=33)$. Data is represented as mean $\pm S E M$; differences were

692 considered significant at $p<0.05$.

693

\begin{tabular}{|c|c|c|c|c|c|}
\hline \multirow{2}{*}{$\#$} & \multirow{2}{*}{ Intrinsic properties } & \multicolumn{2}{|c|}{ CA1 } & \multicolumn{2}{c|}{ CA3 } \\
\cline { 3 - 6 } & & Control & Mutant & Control & Mutant \\
\hline 1 & RMP $(\mathrm{mV})$ & $-55.36 \pm 0.58$ & $-54.64 \pm 0.64$ & $-56.07 \pm 0.82$ & $-56.49 \pm 0.92$ \\
\hline 2 & Input resistance $(\mathrm{M} \Omega)$ & $284.27 \pm 21.6$ & $262.82 \pm 22.72$ & $331.73 \pm 23.54$ & $272.99 \pm 39.14$ \\
\hline 3 & Time constant $(\mathrm{ms})$ & $21.79 \pm 1.76$ & $23.58 \pm 1.85$ & $32.23 \pm 7.33$ & $44.20 \pm 4.56$ \\
\hline 4 & Rheobase $(\mathrm{pA})$ & $11.54 \pm 3.17$ & $18.95 \pm 3.66$ & $18.95 \pm 3.32$ & $19.33 \pm 4.19$ \\
\hline
\end{tabular}




\section{FIGURE LEGENDS}

695

696

697

698

699

700

701

702

703

704

705

706

707

708

709

710

711

712

713

714

715

716

\section{Figure 1: Nestin-cre;Pik3ca ${ }^{E 545 K}$ mutant brains show higher neural excitability}

(A) Schematic shows electrode placement for EEG-ECoG recordings in P70 Nestincre;Pik3ca ${ }^{E 545 K}$ and control littermates. LFP, local field potential. (B,C) Compared to controls, the mutants showed significantly higher frequency of regional $(r)$ spikes and train of spikes/polyspikes in neocortex (black traces) and hippocampus (blue traces). (D) In the mutant, interictal spike frequency was significantly higher in hippocampus (blue box), compared to those generated in neocortex (orange box) or generalized in both regions (green box) $(F=46.65$, degrees of freedom $(d f)=27)$. (E,F) Power spectrum analysis displayed increased activity in mutant, as emphasized in the representative magnified segments. (G,H) Mutant hippocampus demonstrated significant higher activity in the gamma frequency range ( $F=3.932, \mathrm{df}=27$; neocortex: $F=26.93$, $\mathrm{df}=27$ ).

Data is represented as mean \pm SEM scatter plots; differences were considered

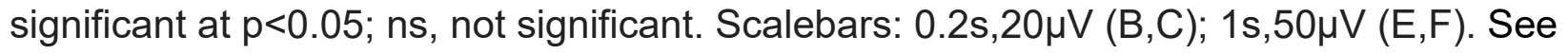
also Figure 1 - figure supplement 1.

\section{Figure 2: Extracellular mutant CA1 recordings demonstrate hyper-}

\section{synchronization}

(A) Schematized flowchart summarizes the acute coronal brain slicing for extracellular field potential recording. (B,C) Representative control (black) and mutant (red) voltage and integrated voltage traces across a $\left[\mathrm{K}^{+}\right]$gradient; comparison indicated significantly higher excitability in the mutant brain. (D,E) Acute extracellular BKM120 administration at constant $7 \mathrm{mM}\left[\mathrm{K}^{+}\right]$aCSF suppressed synchronized ictal bursts in mutant CA1 field 
717 within $\sim 20-30 \mathrm{~min}$, with minimal effect on the control hippocampal slices. Scalebars:

Figure 3: Mutant hippocampal neurons produce increased epileptiform burst

(A) Flowchart shows acute horizontal brain slicing for whole-cell recording. (B-E) Traces

spontaneous cellular activity; respective pie charts marked proportion of recorded cells.

Mutant CA1 and CA3 exhibited significantly higher proportions of burst-firing cells

$727(\mathbf{F}, \mathbf{G})$ relative to controls, spontaneous tonic spike frequencies were significantly higher was significantly higher in mutant CA1 (CA1: $t=2.244, \mathrm{df}=29.38$; CA3: $\mathrm{t}=0.1561$, $\mathrm{df}=6.754) .(\mathbf{H})$ Plateau potential shift (PPS) in mutant bursting cells, as depicted in ( $\left.\mathbf{H}^{\prime}\right)$, was significantly higher in CA1 $(\mathrm{t}=2.586, \mathrm{df}=8.118)$ but similar in CA3 $(\mathrm{t}=0.2436$, $\mathrm{df}=5.110)$, compared to respective controls. $(\mathrm{I}-\mathrm{L})$ Representative evoked voltage traces of control and mutant showed tonic and burst firing in response to current steps. (M)

734 Evoked recording also marked significantly higher bursting cell proportions in the 735 mutant. Data is represented as pie charts, \% bar graphs and mean \pm SEM scatter plots;

736 differences were considered significant at $p<0.05$; ns, not significant. Scalebars:

737 1s,20mV (B,D); 0.1s,20mV (H', I-L). See also Figure 3 - figure supplements 1-2. 


\section{Figure 4: Pik3ca-related burst characteristics are dependent on cell-intrinsic}

\section{calcium and potassium channel regulation}

(A-D) Blocking calcium channels by extracellular cadmium $\left(\mathrm{Cd}^{2+}\right)$ significantly altered intrinsic bursting pattern of mutant neurons including burst frequency $(t=3.267, d f=3)$ and PPS ( $t=4.172, d f=3) .(E-H)$ Representative traces and respective pie charts show types of cellular activity in control and mutant CA1 and CA3 neurons after administering cesium intracellularly. In response to cesium, tonic firing cells were significantly reduced and original differences in CA1 and CA3 cell proportions between control and mutant were normalized. (I) $\mathrm{Cs}^{+}$-induced burst frequency was significantly higher in mutant CA3 than those in respective controls $(F=26.31, \mathrm{df}=21)$; unlike normal spontaneous state, no such difference was observed in CA1. (J-L) Intracellular cesium lowered the spontaneously enhanced mutant PPS in CA1 to control levels $(F=4.003, \mathrm{df}=20)$, while having no effect on RMP (CA1: $t=1.308, d f=27.32$; CA3: $t=0.2616$, $d f=6.816)$ or input resistance $(\mathrm{F}=2.936, \mathrm{df}=42)$ in both control and mutant neurons. Data is represented as pie charts, \% bar graphs and mean \pm SEM scatter plots; differences were considered significant at $p<0.05$; ns, not significant. Scalebars: 1s,20mV (A,E,F). See also Figure 4 - figure supplement 1.

\section{Figure 5: Acute inhibition of Pik3ca or Akt suppresses hyperactivity in mutant} cells

(A) Schematic of simplified PI3K-AKT-MTOR pathway, marking targets of action for BKM120, AZD5363 and RAD001. Representative traces demonstrate differential action of BKM120 (B), AZD5363 (F) and RAD001 (J) on Nestin-cre;Pik3caE545K hippocampal 
762 neurons, ranging from being unaffected to change in frequency/pattern to silencing, as

763 quantitated respectively in (C,G,K). (D,E,H,I) BKM120 and AZD5363 significantly

764 reduced mutant burst frequency (BKM120: $F=8.937, \mathrm{df}=38 ;$ AZD5363: $F=43.50, \mathrm{df}=20)$

765 and PPS (BKM120: $F=24.39, d f=36 ; A Z D 5363: t=6.386, d f=6)$ in both CA1 and CA3.

766 (E', I') Insets show activity traces of mutant bursting cell before (red) and after BKM120

767 (blue) or AZD5363 (pink) administration. (L,M) Acute RAD001 treatment had no overt

768 effect on the mutant burst frequency $(t=0.4414, d f=4)$ or PPS $(t=0.7692, d f=4)$. Data is

769 represented as \% bar graphs and mean \pm SEM scatter plots; differences were

770 considered significant at $p<0.05$; ns, not significant. Scalebars: $1 \mathrm{~s}, 20 \mathrm{mV}(\mathrm{B}, \mathrm{F}, \mathrm{J})$;

$7710.05 \mathrm{~s}, 20 \mathrm{mV}\left(\mathrm{E}^{\prime}, \mathrm{I}^{\prime}\right)$. See also Figure 5 - figure supplements 1-2. 


\section{Figure Supplements}

774 Figure 1 - figure supplement 1: ECoG-LFP traces show different types of epileptiform activity in Nestin-cre;Pik3ca ${ }^{E 545 K}$ brains

$776(\mathbf{A}, \mathbf{B})$ Examples of different types of isolated spiking events in the neocortex and

777 hippocampus taken from 2 different mutant mice showed a varied range of spike nature

778 - in frequency, source of origin and amplitude. (C) Example of train of spiking events in

779 the hippocampus and left cortex. (D) Example of low amplitude, high frequency

780 brushing events. g, generalized; r, regional. Scalebars: 0.5s,50mV (A,B); 2s,50mV

$781(\mathrm{C}, \mathrm{D})$.

Figure 2 - figure supplement 1: Enhanced neuronal network excitability in mutant

CA1 across an extracellular potassium gradient

(A) Bar graphs depicted normalized baseline shift of integrated field potential traces in mean \pm SEM bar graphs; differences were considered significant at $p<0.05$; ns, not significant. 
subcategories were not overtly different in control and mutant $C A 1$ and $C A 3$ regions $(F=$ $7.355 \mathrm{e}^{-12}$; $\mathrm{df}=6$ ); burst clusters were only seen in mutant cells. (C) Representative trace demonstrates how burst duration and inter-burst interval were calculated. (D,E) In both CA1 and CA3, average (avg.) burst duration (CA1: $t=0.9644, \mathrm{df}=6.793$; CA3: $\mathrm{t}=0.3508$, $d f=6.229)$ and inter-burst interval $(C A 1: t=0.1263, d f=22.31 ; C A 3: t=1.485, d f=10.73)$ were not significantly different between control and mutant neurons. Data is represented as mean \pm SEM scatter plots; differences were considered significant at $p<0.05$; ns, not significant; PPS, plateau potential shift. Scalebars: $0.2 \mathrm{~s}, 20 \mathrm{mV}(\mathrm{a}), 1 \mathrm{~s}, 20 \mathrm{mV}$ (c).

\section{Figure 3 - figure supplement 2: Resting membrane potentials and threshold}

\section{currents for hippocampal neuronal firing remain unchanged by Pik3ca} overactivation

(A-C) Resting membrane potential (RMP) was not significantly different between control and mutant neurons, both in CA1 $(t=0.8331, d f=94.99)$ and CA3 $(t=0.3438, d f=78.53)$, as well as among different firing types (CA1: $F=0.9136, d f=90 ; C A 3: F=2.829, d f=75)$. (D,E) No significant differences in evoked tonic spike frequencies were observed in the tested range of input depolarizing current (0-90pA), between control and mutant CA1 and CA3 neurons (CA1: $F=13.07, d f=320 ; C A 3: F=4.844, d f=270)$. $(F)$ No overt differences in the current inducing the first burst were observed between control and mutant $(\mathrm{CA} 1: \mathrm{t}=1.744, \mathrm{df}=20.29$; $\mathrm{CA3}: \mathrm{t}=0.8493, \mathrm{df}=2.439)$. Data is represented as mean \pm SEM scatter and line plots; differences were considered significant at $p<0.05$; ns, not significant. 
820 Figure 4 - figure supplement 1: Pik3ca-related epileptiform activity is not

821

822

823

824

825

826

827

828

829

830

831

\section{dependent on glutamatergic or GABAergic inputs}

(A) Representative spontaneous mutant trace and traces of the same cell posttreatment with glutamatergic receptor antagonists (CPP, CNQX) and with GABA antagonist gabazine showed no significant change in firing pattern. (B-D) Large proportion of mutant cells remained unaffected after being blocked from external glutamatergic or GABAergic inputs. (E-L) No significant differences in normalized plateau potential shift (PPS; CPP: F=3.391, df=12; CNQX: F=1.432, df=12; Gabazine: $t=0.3904, d f=4$ ) or in tonic (CPP: $t=1.876, d f=7 ; C N Q X: F=0.2766, d f=20 ;$ Gabazine: $F=0.0001130, d f=16$ ) and burst frequencies (CPP: $F=0.5140, d f=16 ; C N Q X: F=5.218$, $\mathrm{df}=16$ ) were observed before and after administration of channel blockers. Data is represented as \% bar graphs and mean \pm SEM scatter plots; differences were considered significant at $p<0.05$; ns, not significant. Scalebar: $1 \mathrm{s,20mV}(\mathrm{A})$.

\section{Figure 5 - figure supplement 1: Acute treatment with BKM120 and AZD5363 has}

\section{differential effect on Nestin-cre;Pik3ca ${ }^{E 545 K}$ neuronal physiological properties} (A-D) Acute BKM120 treatment did not significantly affect RMP $(F=0.9268, d f=42)$, tonic rheobase current $(t=0.000, d f=8)$, average burst duration $(C A 1: t=1.264, d f=8 ; C A 3$ : $t=0.6150, d f=11)$ or inter-burst interval $(C A 1: t=1.889, d f=8 ; C A 3: t=1.160, d f=10)$ in mutant hippocampal neurons. (E-H) Acute AKT inhibition by AZD5363 had no effect on the mutant RMP $(F=0.3316, d f=20)$ or rheobase current $(t=0.3859, d f=7)$, but significantly attenuated the average burst duration $(t=4.052, d f=5)$ and inter-burst interval ( $t=4.597, d f=6)$, largely by suppressing bursts or silencing the cells. $(\mathbf{I}, \mathbf{J})$ Plots 
843 marked percentage of mutant CA3 "bursting" cells undergoing changes as a function of

844 time, in response to acute administration of BKM120 (I) and AZD5363 (J). (K) Mutant

845 plateau frequency significantly dropped as a function of time, where Omin marked the

846 time of administration of BKM120/AZD5363 onto the brain slice. Data is represented as

847 mean \pm SEM scatter plots; differences were considered significant at $p<0.05$; ns, not

848 significant.

850 Figure 5 - figure supplement 2: Acute treatment with RAD001 has no overt effect on mutant neuronal physiological properties

852 (A-D) Acute BKM120 treatment did not significantly affect the RMP $(t=1.327, d f=4)$, 853 average burst duration $(t=1.073, d f=4)$, inter-burst interval $(t=0.4023, d f=4)$ or rheobase 854 current $(t=1.000, d f=4)$ in mutant CA1 neurons. (E) Representative Western blots bands 855 of pAKT_S473, pan-AKT, pS6-S235/236 and RPS6 (total S6) are demonstrated across 856 different treatment (DMSO, BKM120, AZD5363, RAD001). (F,G) Quantifications of 857 normalized ratios of phosphoproteins over total proteins showed significant reduction of 858 pAKT_S473 in response to acute BKM120 and RAD001 treatment but not post859 AZD5363 ( $F=22.98, d f=32) ;$ pS6_S235/236 in mutant had a decreasing trend in 860 response to all pathway drugs $(F=4.485, \mathrm{df}=32)$. Data is represented as mean $\pm \mathrm{SEM}$ 861 scatter plots and bar graphs; differences were considered significant at $p<0.05$; ns, not 862 significant. 
A

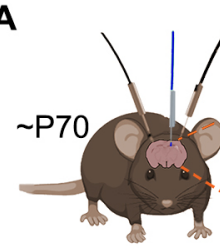

D
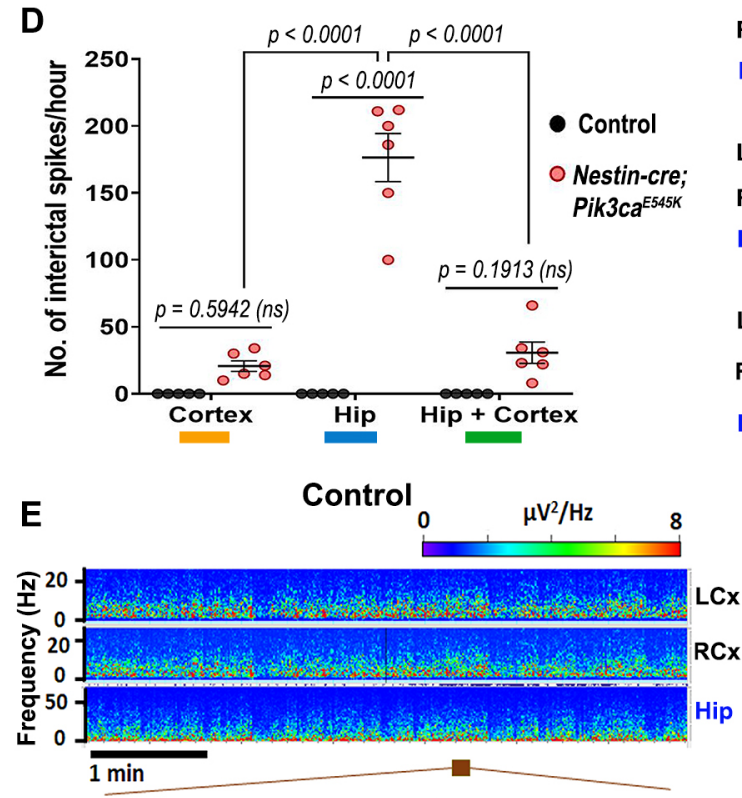

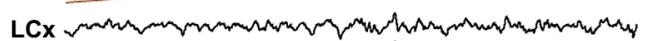

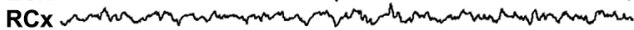

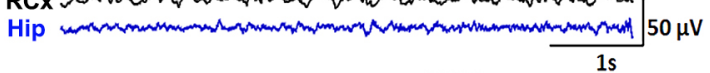

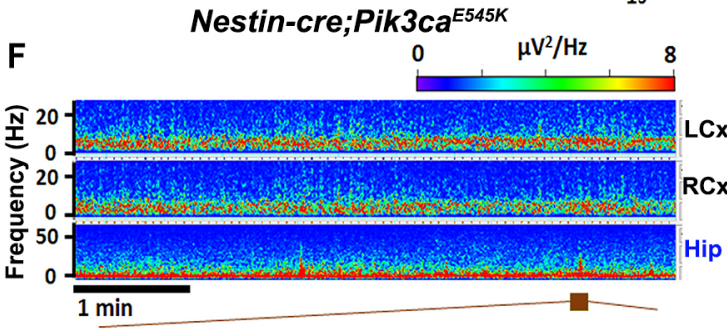

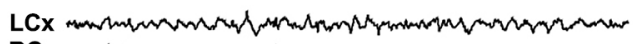

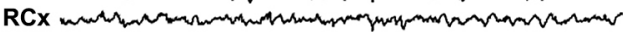

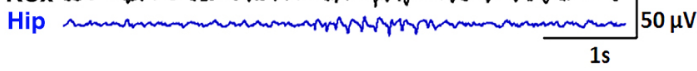

Figure 1
Control

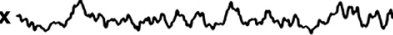

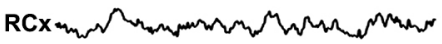

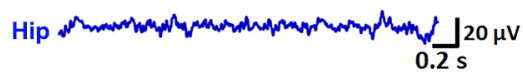

C Nestin-cre;Pik3ca ${ }^{\text {E45KK }}$

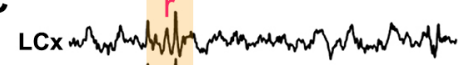

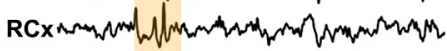

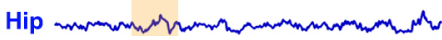

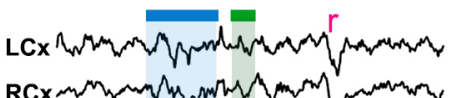

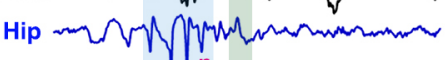

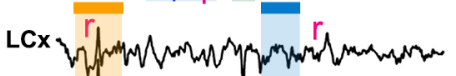

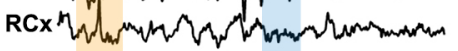

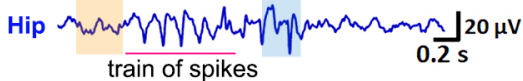

\section{G}

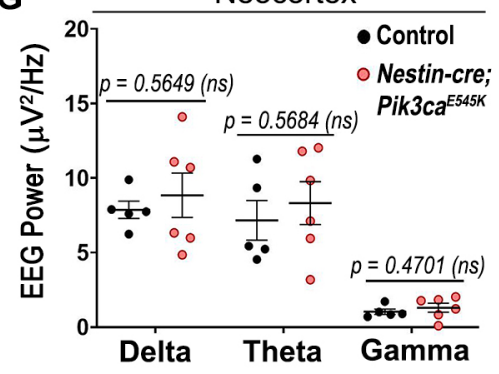

H

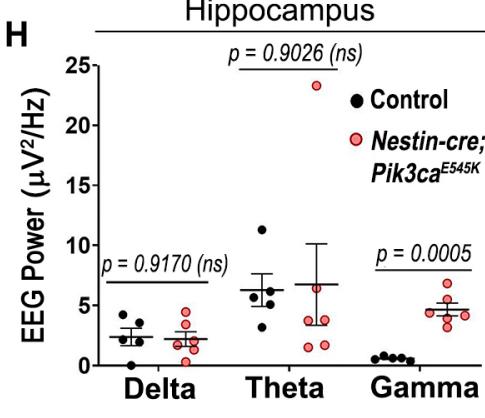


bioRxiv preprint doi: https://doi.org/10.1101/2021.03.03.433821; this version posted May 16, 2021. The copyright holder for this preprint (which was not certified by peer review) is the author/funder, who has granted bioRxiv a license to display the preprint in perpetuity. It is made available under aCC-BY-NC-ND 4.0 International license.

A
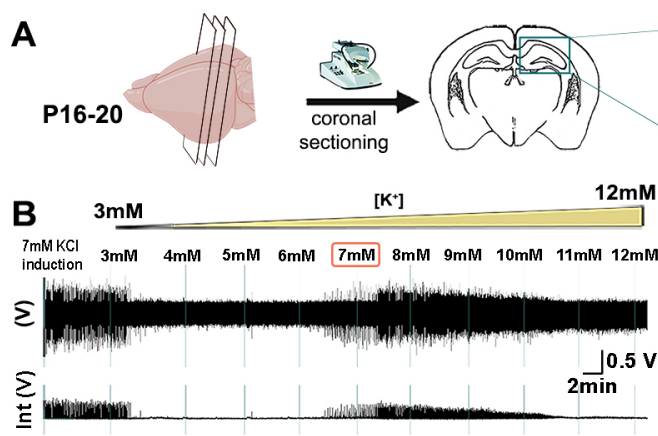

$7 \mathrm{mMKCl} 3 \mathrm{mM} \quad 4 \mathrm{mM} \quad 5 \mathrm{mM} \quad 6 \mathrm{mM} \quad 7 \mathrm{mM} \quad 8 \mathrm{mM} \quad 9 \mathrm{mM} \quad 10 \mathrm{mM} 11 \mathrm{mM} 12 \mathrm{mM}$ induction
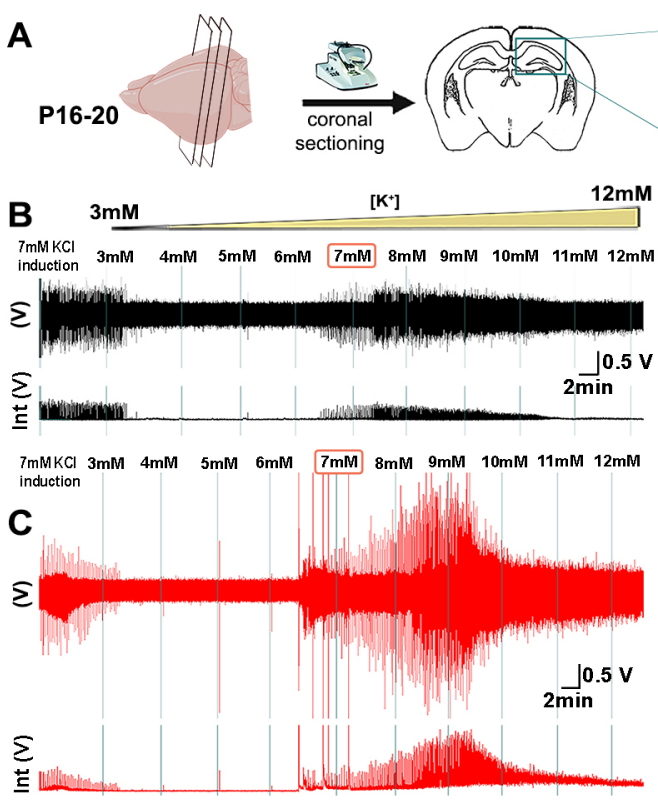
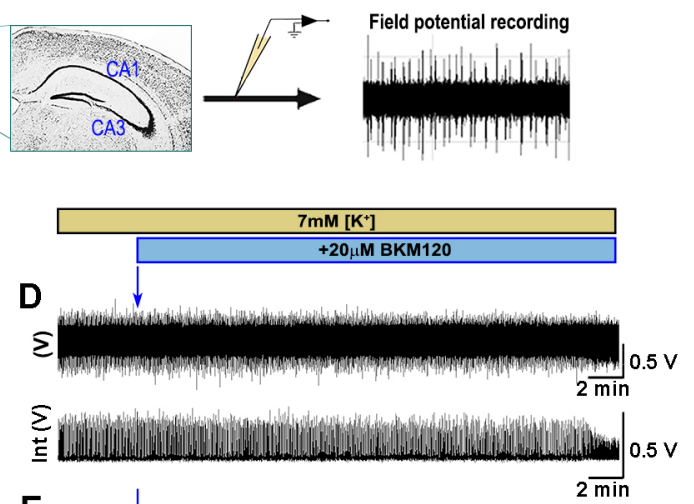

E
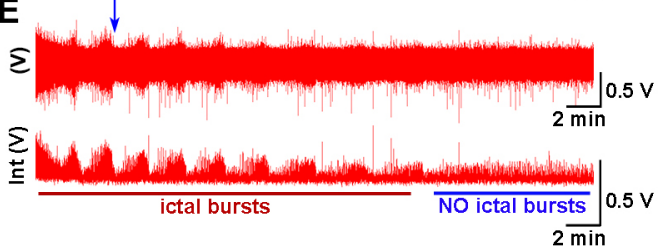

Control Nestin-cre;Pik3ca ${ }^{\mathrm{E545K}}$

Figure 2 


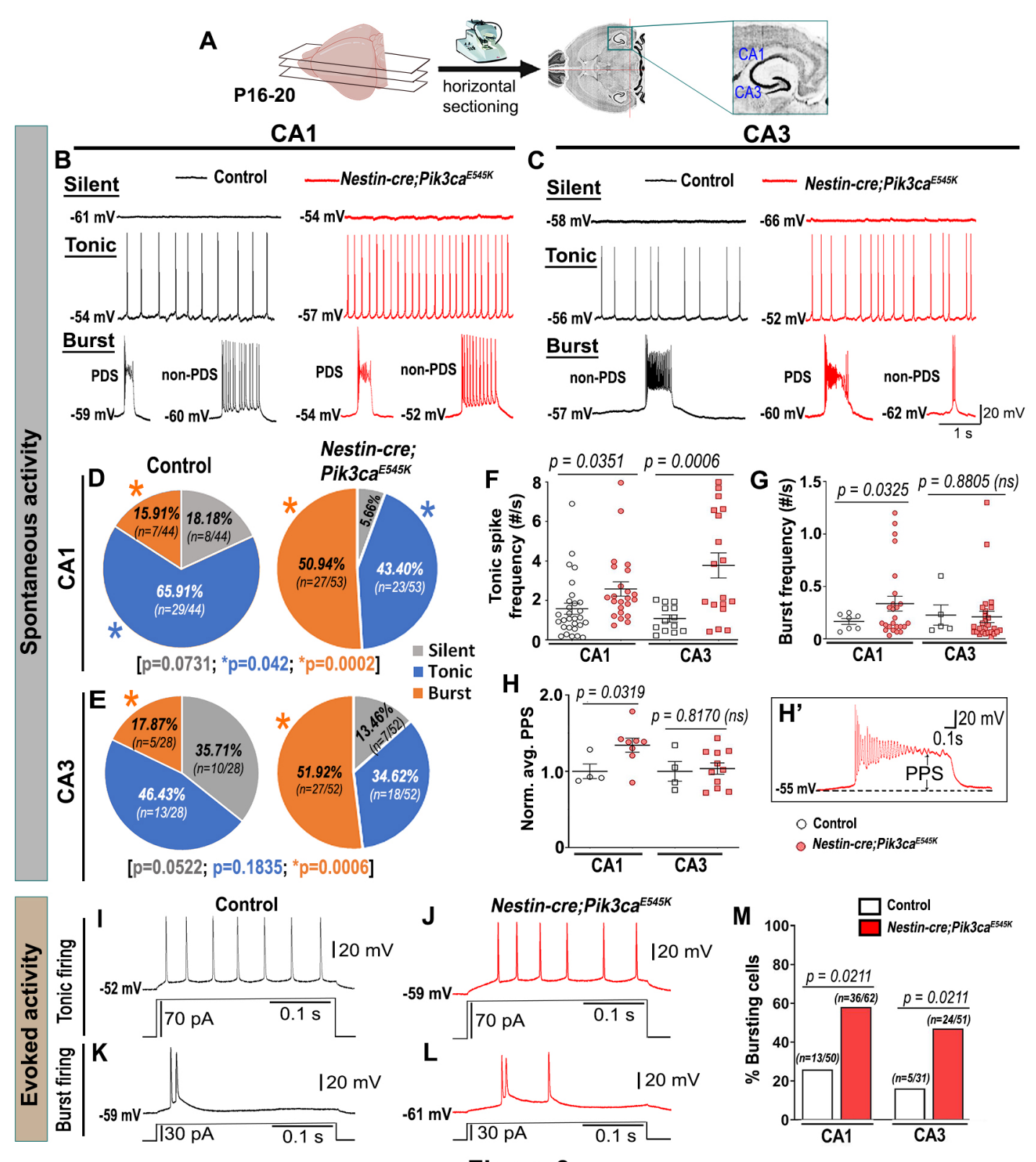

Figure 3 
bioRxiv preprint doi: https://doi.org/10.1101/2021.03.03.433821; this version posted May 16, 2021. The copyright holder for this preprint (which was not certified by peer review) is the author/funder, who has granted bioRxiv a license to display the preprint in perpetuity. It is made available under aCC-BY-NC-ND 4.0 International license.

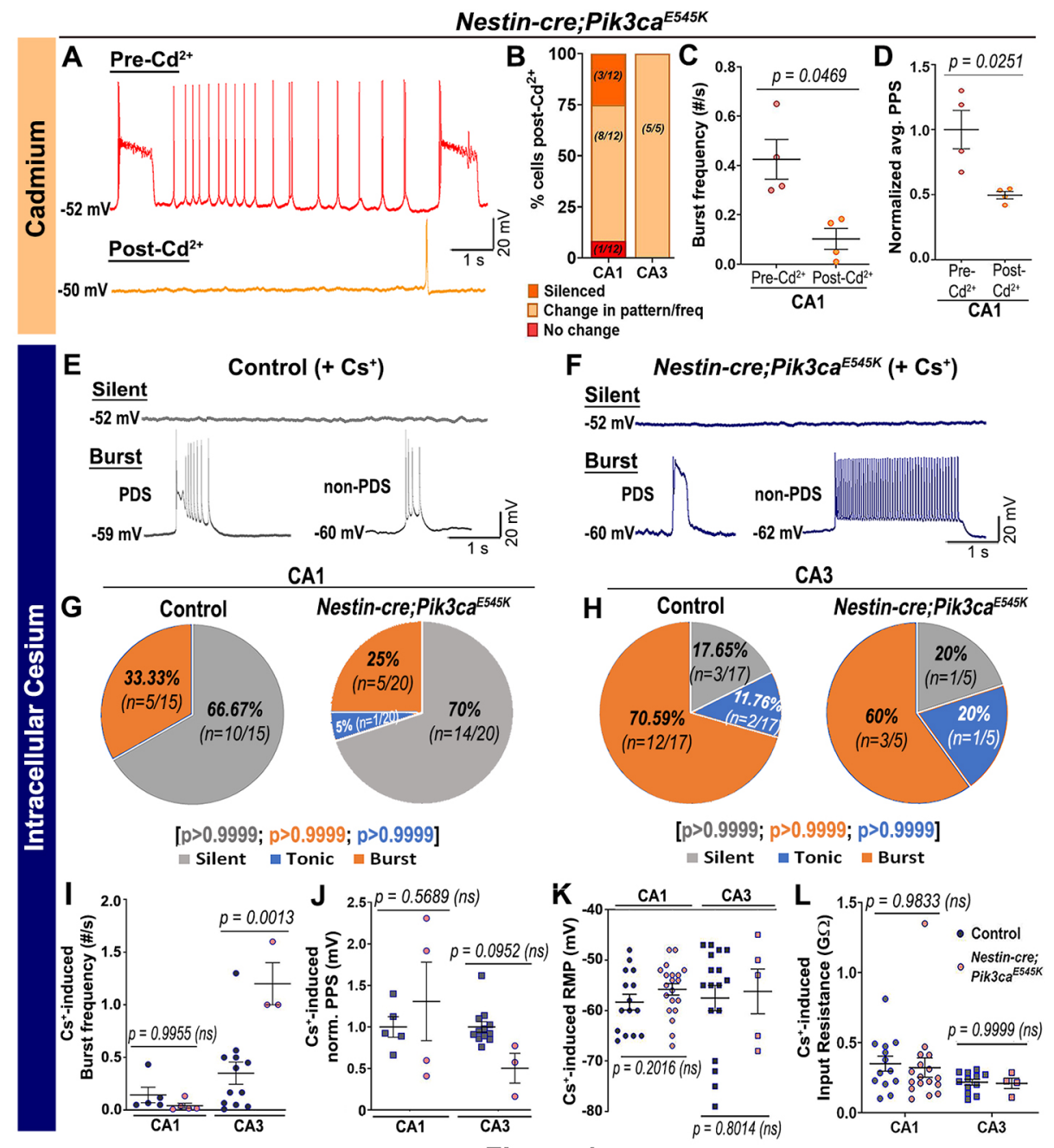

Figure 4 
bioRxiv preprint doi: https://doi.org/10.1101/2021.03.03.433821; this version posted May 16, 2021. The copyright holder for this preprint (which

was not certified by peer review) is the author/funder, who has granted bioRxiv a license to display the preprint in perpetuity. It is made available under aCC-BY-NC-ND 4.0 International license.

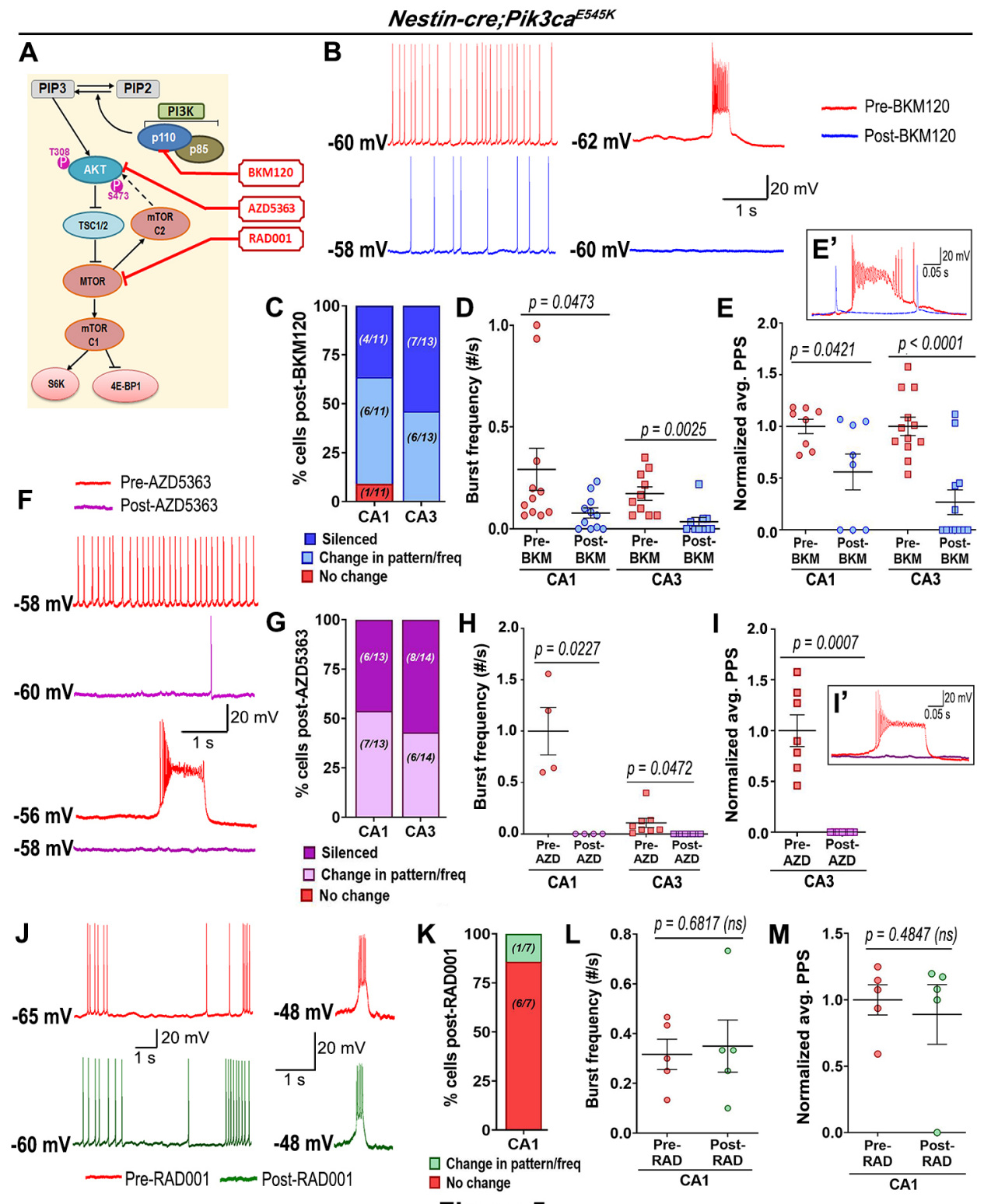

Figure 5 


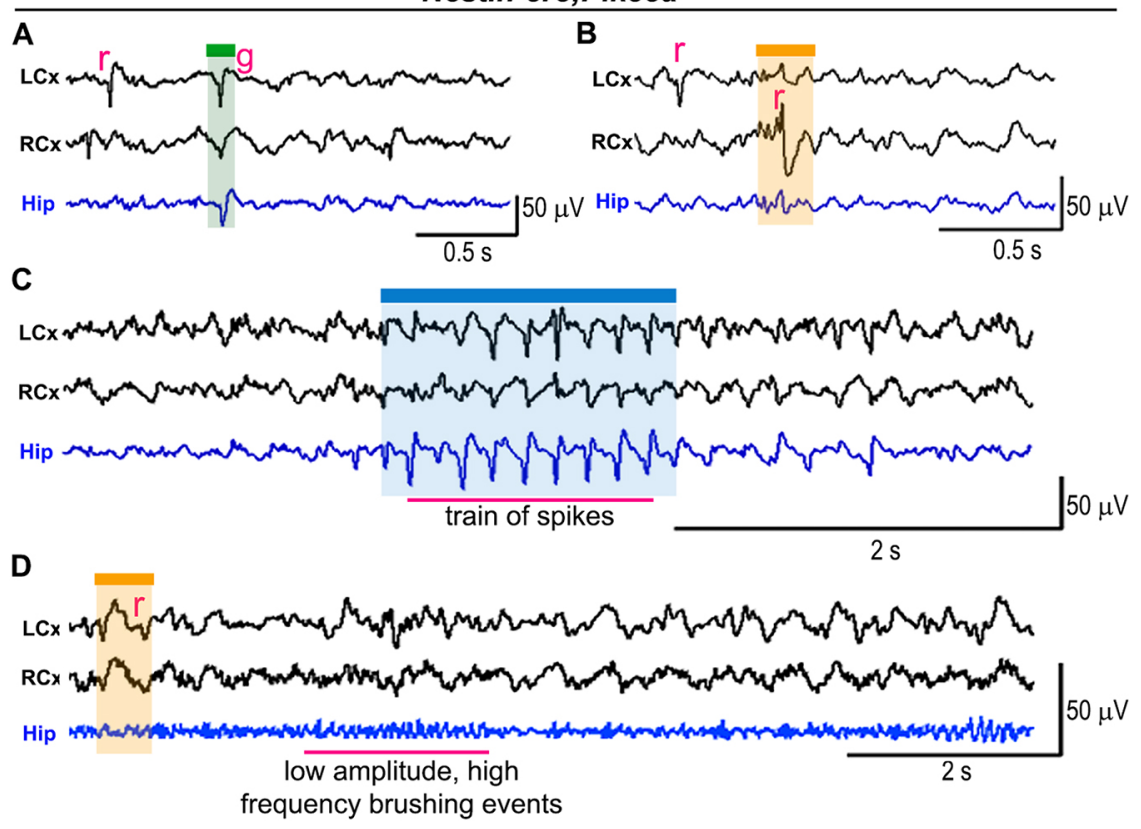

Figure 1 - figure supplement 1 

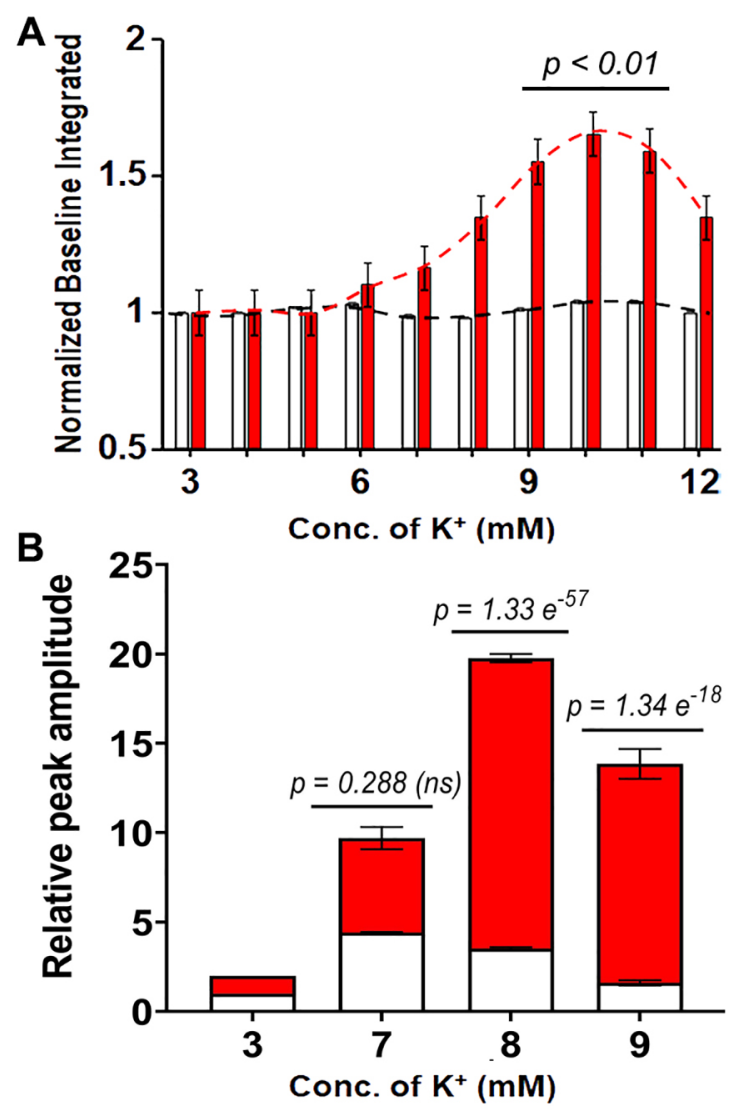

$\square$ Control $\square$ Nestin-cre;Pik3ca ${ }^{E 545 K}$

Figure 2 - figure supplement 1 
bioRxiv preprint doi: https://doi.org/10.1101/2021.03.03.433821; this version posted May 16, 2021. The copyright holder for this preprint (which

was not certified by peer review) is the author/funder, who has granted bioRxiv a license to display the preprint in perpetuity. It is made available under aCC-BY-NC-ND 4.0 International license.

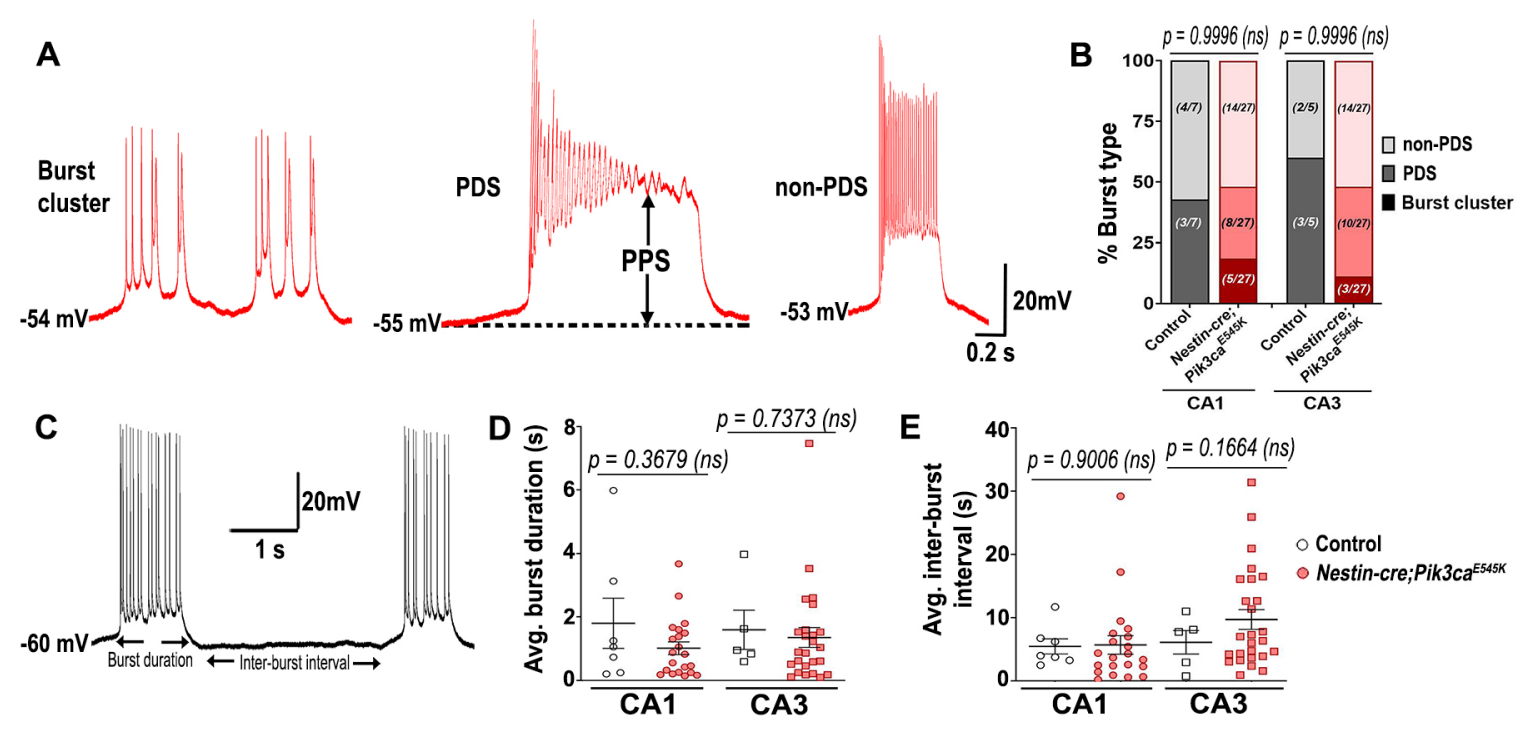

Figure 3 - figure supplement 1 


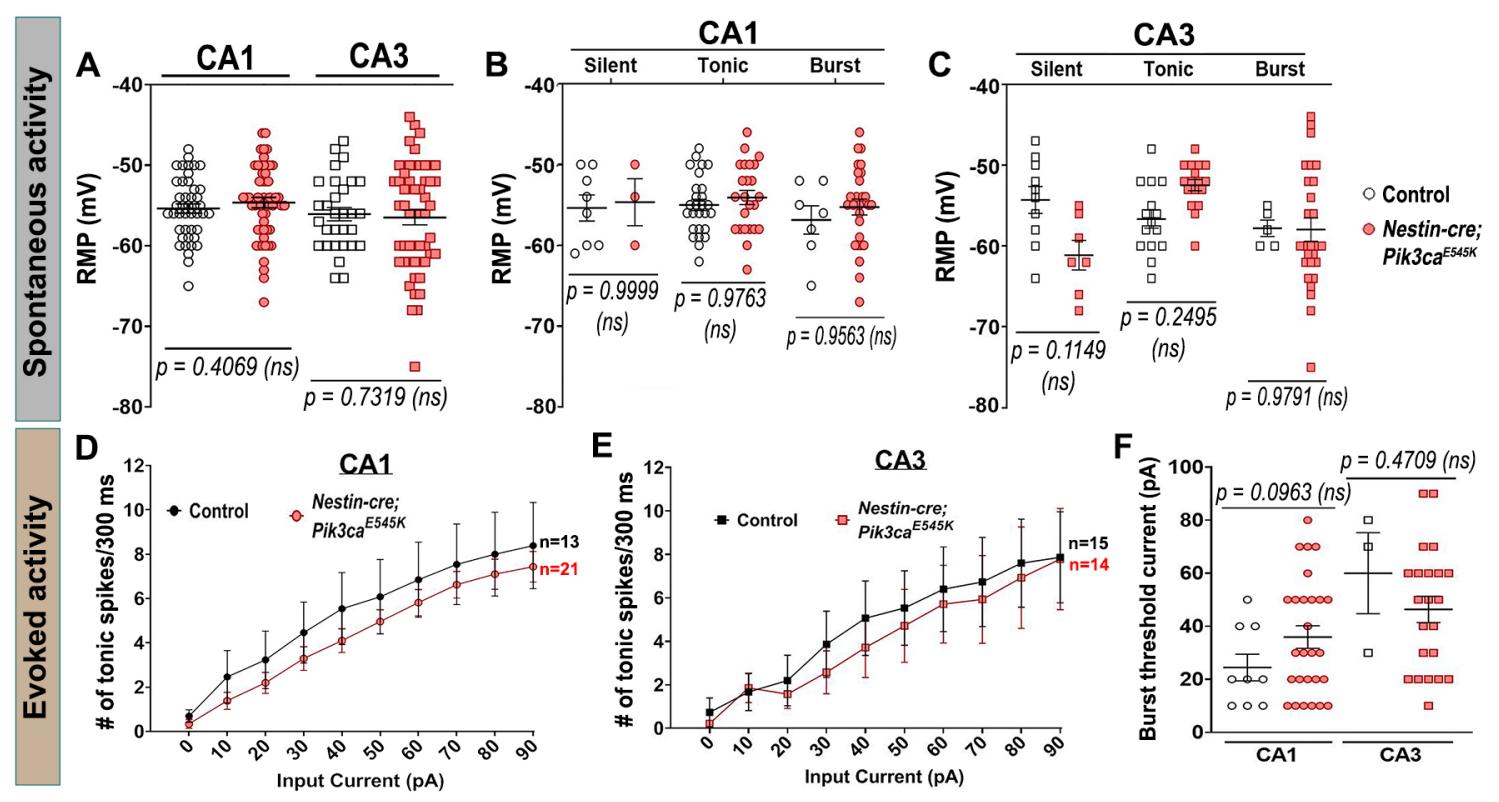

Figure 3 - figure supplement 2 
Nestin-cre;Pik3ca ${ }^{E 545 K}$

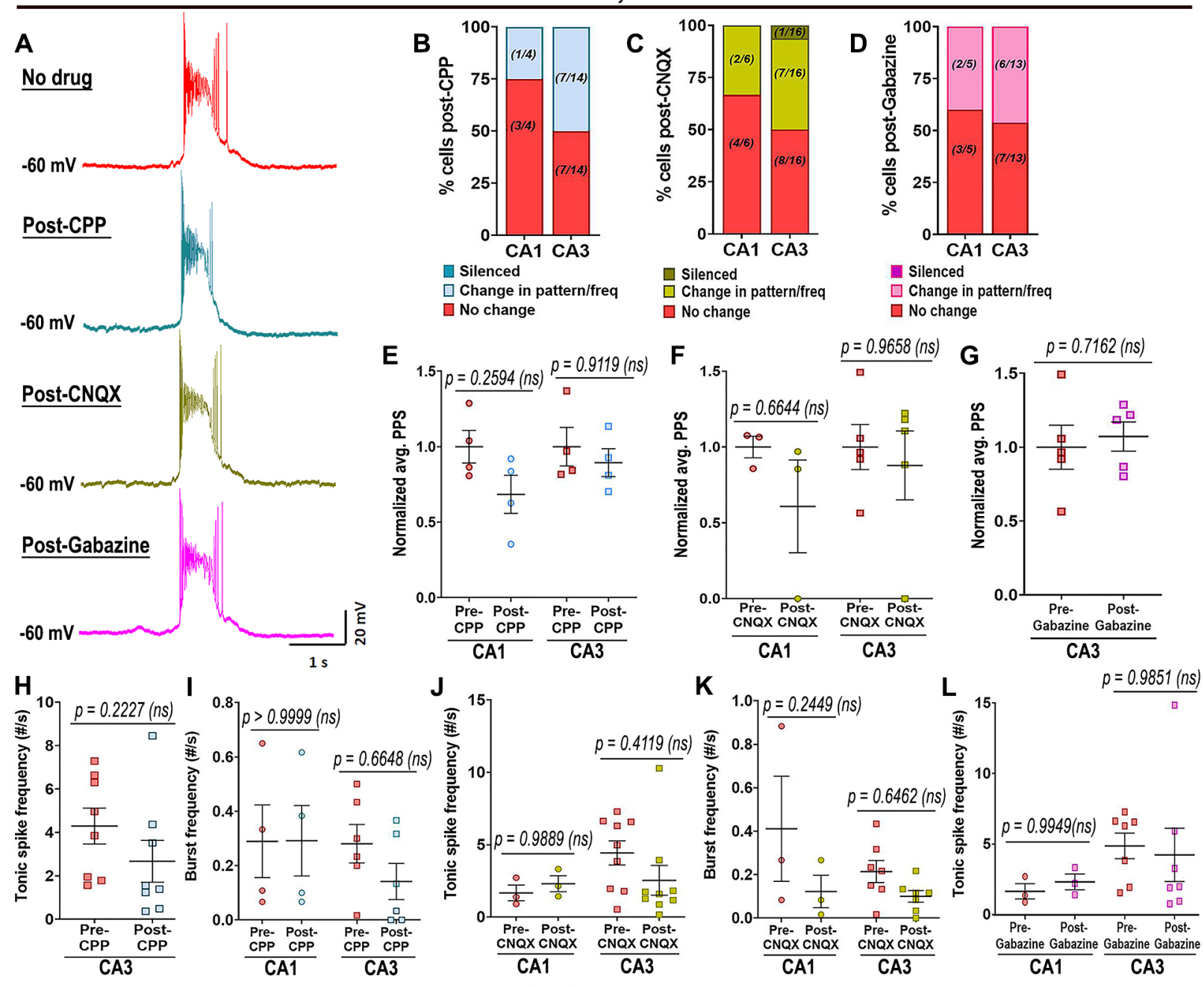

Figure 4 - figure supplement 1 
bioRxiv preprint doi: https://doi.org/10.1101/2021.03.03.433821; this version posted May 16, 2021. The copyright holder for this preprint (which was not certified by peer review) is the author/funder, who has granted bioRxiv a license to display the preprint in perpetuity. It is made available under aCC-BY-NC-ND 4.0 International license.

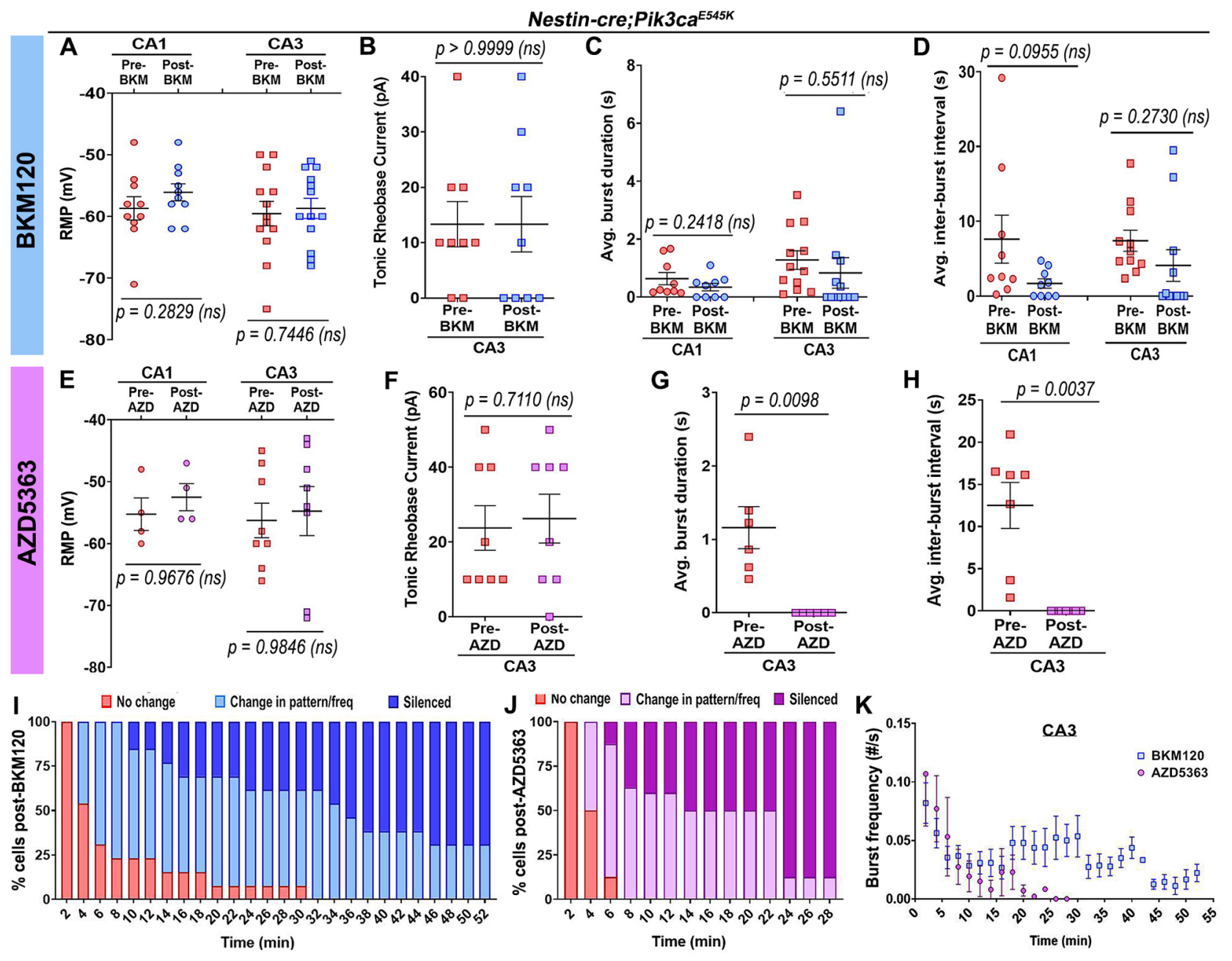

Figure 5 - figure supplement 1 
bioRxiv preprint doi: https://doi.org/10.1101/2021.03.03.433821; this version posted May 16, 2021. The copyright holder for this preprint (which

was not certified by peer review) is the author/funder, who has granted bioRxiv a license to display the preprint in perpetuity. It is made available under aCC-BY-NC-ND 4.0 International license.
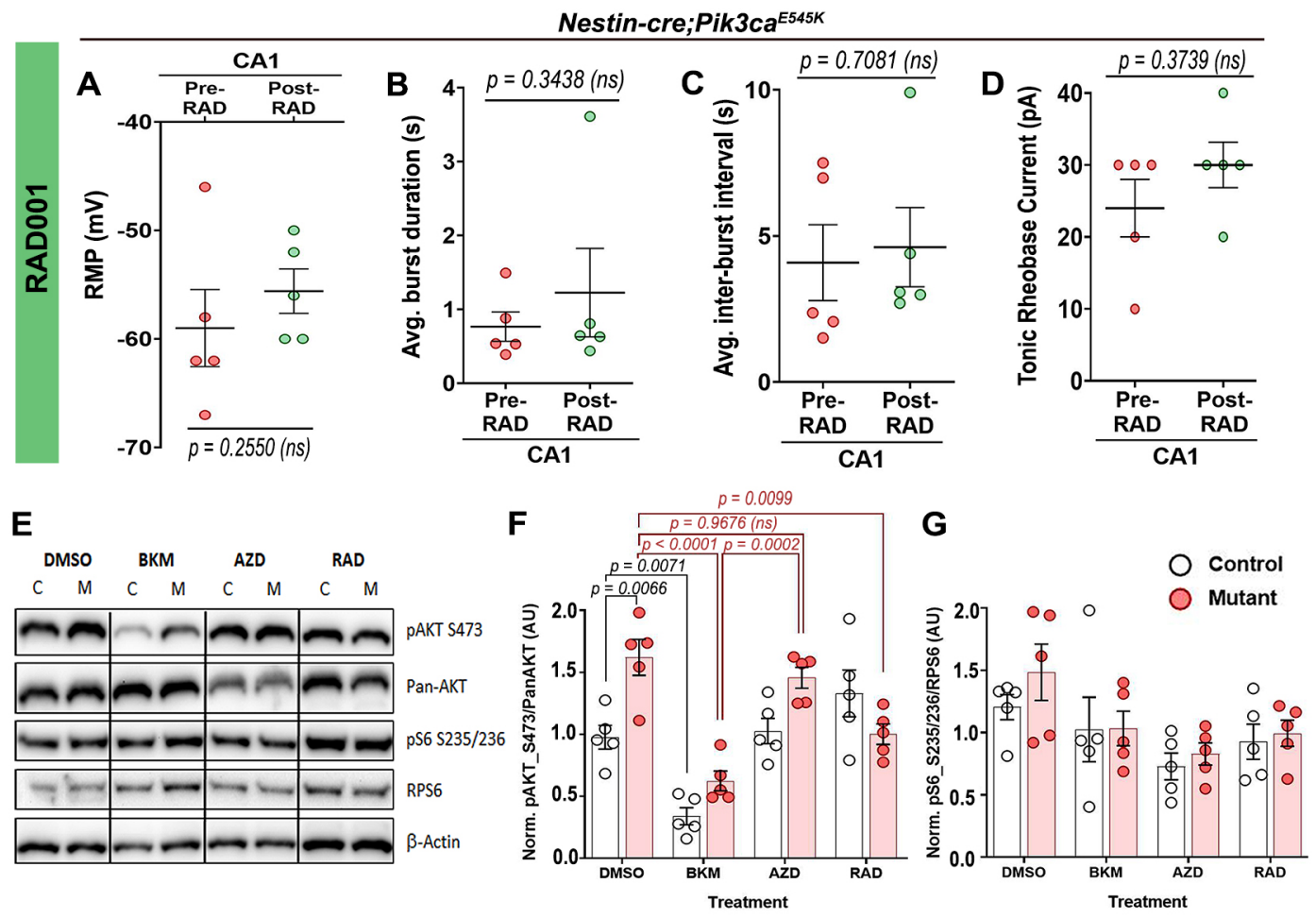

Figure 5 - figure supplement 2 